\title{
Detection of Breakpoints in Volatility
}

\author{
Viviana Fernández ${ }^{1}$
}

Universidad de Chile

\begin{abstract}
In this article, we test for the presence of structural breaks in volatility by two alternative approaches: the Iterative Cumulative Sum of Squares (ICSS) algorithm and wavelet analysis. Specifically, we look at the effect of the outbreak of the Asian crisis and the terrorist attacks of September 11, 2001 on Emerging Asia, Europe, Latin America and North America's stock markets. In addition, we focus on the behavior of interest rates in Chile after the Central Bank switched its monetary policy interest rate from an inflation-indexed to a nominal target in August 2001.
\end{abstract}

Our estimation results show that the number of shifts detected by the two methods is substantially reduced when filtering out the data for both conditional heteroskedasticity and serial correlation.

JEL: C22, G15 Keywords: ICSS algorithm, wavelet analysis, volatility breakpoints.

\footnotetext{
' Funds provided by an institutional grant of the Hewlett Foundation to CEA are greatly acknowledged. All remaining errors are the author's.
} 


\section{Extracto}

En este artículo detectamos la presencia de quiebres estructurales en varianza con dos métodos alternativos: la suma iterada de cuadrados acumulativos (ICSS) y el análisis de wavelets. Concretamente nos centramos en el efecto de la crisis asiática y del ataque terrorista del 11 de septiembre de 2001 sobre los mercados accionarios de Asia Emergente, Europa, Latinoamérica y Norteamérica. Además analizamos el comportamiento de las tasas de interés en Chile tras la nominalización instaurada por el Banco Central en agosto de 2001.

Nuestras estimaciones muestran que el número de quiebres detectados por ambos métodos se reduce sustancialmente cuando filtramos los datos por heterocedasticidad condicional y correlación serial.

JEL: C22, G15 Palabras clave : algoritmo ICSS, análisis de wavelets, quiebres en volatilidad

\section{Introduction}

To date, there is an extensive literature on the behavior of volatility of assets returns. Indeed, the GARCH model and numerous variations of it have been fitted to different financial time series around the world to account for the existence of conditional heteroskedasticity (see, for instance, the survey by Poon and Granger, 2003). However, less attention has been paid to the detection of multiple shifts in unconditional variance over time. For example, Lamoureux and Lastrapes (1990) conclude that persistence in variance may be overstated by not accounting for deterministic structural breakpoints in the variance model.

A relatively recent approach to testing for volatility shifts is Inclan and Tiao (1994)'s Iterative Cumulative Sums of Squares (ICSS) algorithm. This algorithm allows for detecting multiple breakpoints in variance in a time series. Aggarwal, Inclan and Leal (1999) present an application of this procedure for emerging markets over 1985-1995. They conclude that most events leading to volatility shifts tended to be local (e.g., the Mexican peso crisis, periods of hyperinflation in Latin America), and that the only global event over the sample that affected several emerging markets was the October 1987 crash. 
However, recent literature has shown that the ICSS algorithm tends to overstate the number of actual structural breaks in variance. Specifically, Bacmann and Dubois (2002) point out that the behavior of the ICSS algorithm is questionable under the presence of conditional heteroskedasticity. They show that one way to circumvent this problem is by filtering the return series by a GARCH $(1,1)$ model, and applying the ICSS algorithm to the standardized residuals. Bacmann and Dubois conclude that structural breaks in unconditional variance are less frequent than it was shown previously.

An alternative approach to testing for homogeneity of variance is wavelet analysis. Wavelet analysis is a refinement of Fourier analysis that was developed in the late 1980's, and which offers a powerful methodology for processing signals, images, and other types of data. In particular, the discrete wavelet transform allows for the decomposition of time series data into orthogonal components with different frequencies. In finance, potential applications of wavelet methods are quantification of spillovers between stock markets at different time horizons, and testing for the presence of structural breaks in volatility in detailed and smooth components of a time series.

Recent applications of wavelets in economics and finance are Ramsey and Lampart (1998), Norsworthy, Li and Gorener (2000), Lee (2001a, 2001b), and Gencay, Whitcher, and Selcuk (2002). Ramsey and Lampart (1998) study the permanent income hypothesis, and conclude that the time-scale decomposition is very important for analyzing economic relationships. Norsworthy, Li and Gorener (2000) and Gencay, Whitcher, and Selcuk (2002) apply wavelet analysis to estimate the systematic risk of an asset (beta). Lee (2001a) studies the interaction between the U.S. and the South Korean stock markets. He finds evidence of price and volatility spillover effects from the U.S. stock market to the Korean stock market, but not vice versa. In turn Lee (2001b) illustrates the use of wavelets for seasonality filtering of time-series data.

This paper is organized as follows. Section 2 gives a brief background on wavelet analysis. Section 3 focuses on detection of breakpoints in volatility by the ICSS algorithm and wavelet methods for a sample of four stock indices (Emerging Asia, Europe, Latin America, and North America), and interest rates series paid on deposits by Chilean banks (nominal and inflation-indexed). We test for variance homogeneity in the original series, and in the series filtered out 
for both conditional heteroskedasticity and serial correlation. Section 4 presents our main conclusions.

The contribution of this article is twofold. First, it provides new evidence that reinforces the importance of controlling for both conditional heteroskedasticity and serial correlation prior to testing for variance homogeneity. Second, it makes a parallel between the ICSS algorithm and wavelet analysis, showing that the latter tends to be more robust. To our knowledge, no one has yet conducted a similar study.

\section{Wavelet Analysis in a Nutshell}

Wavelets or short waves are similar to sine and cosine functions in that they also oscillates about zero. However, as its name indicates, oscillations of a wavelet fade away around zero, and the function is localized in time or space. ${ }^{2}$ In wavelet analysis, a signal (i.e., a sequence of numerical measurements) is represented as a linear combination of wavelet functions.

Unlike Fourier series, wavelets are suitable building-block functions for signals whose features change over time, and for non-smooth signals. A wavelet allows for decomposing a signal into multi-resolution components: fine and coarse resolution components.

There are father wavelets $\phi$ and mother wavelets $\psi$ such that

$$
\int \phi(t) d t=1 \quad \int \psi(t) d t=0
$$

Father wavelets are good at representing the smooth and low-frequency parts of a signal, whereas mother wavelets are good at representing the detailed and high-frequency parts of a signal. The most commonly used wavelets are the orthogonal ones (i.e., haar, daublets, symmelets, and coiflets). In particular, the orthogonal wavelet series approximation to a continuous signal $f(t)$ is given by

$$
\mathrm{f}(\mathrm{t}) \approx \sum_{\mathrm{k}} \mathrm{s}_{J, \mathrm{k}} \phi_{J, \mathrm{k}}(\mathrm{t})+\sum_{\mathrm{k}} \mathrm{d}_{J, \mathrm{k}} \psi_{J, \mathrm{k}}(\mathrm{t})+\sum_{\mathrm{k}} \mathrm{d}_{J-1, \mathrm{k}} \psi_{J-1, \mathrm{k}}(\mathrm{t})+\ldots+\sum_{\mathrm{k}} \mathrm{d}_{1, \mathrm{k}} \psi_{1, \mathrm{k}}(\mathrm{t})
$$

where $\mathrm{J}$ is the number of multi-resolution components or scales, and $\mathrm{k}$ ranges from 1 to the number of coefficients in the corresponding component. The coefficients $s_{J, k}, d_{J, k}, \ldots, d_{1, k}$ are the wavelet transform coefficients, whereas the

\footnotetext{
${ }^{2}$ Mathematically, a function $\bar{\omega}($.$) defined over the entire real axis is called a wavelet if \varpi(t) \rightarrow 0$ as $t \rightarrow \pm \infty$.
} 
functions $\phi_{j, k}(t)$ and $\psi_{j, k}(t)$ are the approximating wavelet functions. These functions are generated from $\phi$ and $\psi$ as follows

$\phi_{j, k}(t)=2^{-j / 2} \phi\left(\frac{t-2^{j} k}{2^{j}}\right) \quad \psi_{j, k}(t)=2^{-j / 2} \psi\left(\frac{t-2^{j} k}{2^{j}}\right)$

The wavelet coefficients can be approximated by the following integrals

$$
\mathrm{s}_{J, \mathrm{k}} \approx \int \phi_{\mathrm{J}, \mathrm{k}}(\mathrm{t}) \mathrm{f}(\mathrm{t}) \mathrm{dt} \quad \mathrm{d}_{\mathrm{j}, \mathrm{k}} \approx \int \psi_{\mathrm{j}, \mathrm{k}}(\mathrm{t}) \mathrm{f}(\mathrm{t}) \mathrm{dt}, \mathrm{j}=1,2, \ldots, \mathrm{J}
$$

These coefficients are a measure of the contribution of the corresponding wavelet function to the total signal. On the other hand, the approximating wavelet functions $\phi_{\mathrm{j}, \mathrm{k}}(\mathrm{t})$ and $\psi_{\mathrm{j}, \mathrm{k}}(\mathrm{t})$ are scaled and translated versions of $\phi$ and $\psi$. As equation (3) indicates, the scale or dilation factor is $2^{\mathrm{j}}$, whereas the translation or location parameter is $2^{j} \mathrm{k}$. As j gets larger, so does the scale factor $2^{\mathrm{j}}$, and the functions $\phi_{j, k}(t)$ and $\psi_{j, k}(t)$ get shorter and more spread out. In other words, $2^{j}$ is a measure of the width of the functions $\phi_{j, k}(t)$ and $\psi_{j, k}(t)$. Likewise, as j increases, the translation step gets correspondingly larger in order to match the scale parameter $2^{\mathrm{j}}$.

Applications of wavelet analysis commonly make use of a discrete wavelet transform (DWT). The DWT calculates the coefficients of the approximation in (2) for a discrete signal of final extent, $f_{1}, f_{2}, . ., f_{n}$. That is, it maps the vector $\mathbf{f}=\left(\mathrm{f}_{1}, \mathrm{f}_{2}, \ldots, \mathrm{f}_{\mathrm{n}}\right)$ ' to a vector $\omega$ of $\mathrm{n}$ wavelet coefficients that contains $\mathrm{s}_{\mathrm{J}, \mathrm{k}}$ and $\mathrm{d}_{\mathrm{j}, \mathrm{k}}, \mathrm{j}=1,2, \ldots, \mathrm{J}$. The $\mathrm{s}_{\mathrm{J}, \mathrm{k}}$ are called the smooth coefficients and the $\mathrm{d}_{\mathrm{j}, \mathrm{k}}$ are called the detail coefficients. Intuitively, the smooth coefficients represent the underlying smooth behavior of the data at the coarse scale $2^{\mathrm{J}}$, whereas the detail coefficients provide the coarse scale deviations from it.

When the length of the data $n$ is divisible by $2^{\mathrm{J}}$, there are $\mathrm{n} / 2$ coefficients $d_{1, k}$ at the finest scale $2^{1}=2$. At the next finest scale, there are $n / 2^{2}$ coefficients $d_{2, k}$. Similarly, at the coarsest scale, there are $n / 2^{J} d_{J, k}$ coefficients and $n / 2^{J} s_{J, k}$ coefficients. Altogether, there are $n\left(\sum_{i=1}^{j} \frac{1}{2^{i}}+\frac{1}{2^{J}}\right)=n$ coefficients. The number of coefficients at a given scale is related to the width of the wavelet function. For instance, at the finest scale, it takes $\mathrm{n} / 2$ terms for the functions $\psi_{1, \mathrm{k}}(\mathrm{t})$ to cover the interval $1 \leq t \leq n$. 
The wavelet coefficients are ordered from coarse scales to fine scales in the vector $\omega$. If $\mathrm{n}$ is divisible by $2^{\mathrm{J}}, \omega$ will be given by

$$
\omega=\left(\begin{array}{c}
\mathbf{s}_{\mathrm{J}} \\
\mathbf{d}_{\mathrm{J}} \\
\mathbf{d}_{\mathrm{J}-1} \\
\vdots \\
\mathbf{d}_{1}
\end{array}\right)
$$

where

$$
\begin{array}{cc}
\mathbf{s}_{\mathrm{J}}= & \left(\mathrm{s}_{\mathrm{J}, 1}, \mathrm{~s}_{\mathrm{J}, 2}, \ldots, \mathrm{s}_{\mathrm{J}, \mathrm{n} / 2^{\mathrm{J}}}\right)^{\prime} \\
\mathbf{d}_{\mathrm{J}}= & \left(\mathrm{d}_{\mathrm{J}, 1}, \mathrm{~d}_{\mathrm{J}, 2}, \ldots, \mathrm{d}_{\mathrm{J}, \mathrm{n} / 2^{\mathrm{J}}}\right)^{\prime} \\
\mathbf{d}_{\mathrm{J}-1}= & \left(\mathrm{d}_{\mathrm{J}-1,1}, \mathrm{~d}_{\mathrm{J}-1,2}, \ldots, \mathrm{d}_{\mathrm{J}-1, \mathrm{n} / 2^{\mathrm{J}-1}}\right)^{\prime} \\
\vdots & \vdots \\
\mathbf{d}_{1}= & \left(\mathrm{d}_{1,1}, \mathrm{~d}_{1,2}, \ldots, \mathrm{d}_{1, \mathrm{n} / 2}\right)^{\prime}
\end{array}
$$

Each of the sets of coefficients $\mathbf{s}_{\mathrm{J}}, \mathbf{d}_{\mathrm{J}}, \ldots, \mathbf{d}_{1}$ is called a crystal.

Expression (2) can be rewritten as

$$
f(t) \approx S_{J}(t)+D_{J}(t)+D_{J-1}(t)+\ldots+D_{1}(t)
$$

where

$$
\begin{aligned}
& S_{J}(t)=\sum_{k} s_{J, k} \phi_{J, k}(t) \\
& D_{J}(t)=\sum_{k} d_{j, k} \psi_{J, k}(t)
\end{aligned}
$$

are denominated the smooth signal and the detail signals, respectively.

The terms in expression (6) represent a decomposition of the signal into orthogonal signal components $\mathrm{S}_{J}(\mathrm{t}), \mathrm{D}_{\mathrm{J}}(\mathrm{t}), \mathrm{D}_{\mathrm{J}-1}(\mathrm{t}), \ldots, \mathrm{D}_{1}(\mathrm{t})$ at different scales. These terms are components of the signal at different resolutions. That is why the approximation in (6) is called a multi-resolution decomposition (MRD). 


\section{Data and Estimation Results}

\section{A. Description of the Data}

We work with four stock indices and four interest rates series. The stock indices are taken from Morgan Stanley: Emerging Asia (China, India, Indonesia, Korea, Malaysia, Pakistan, Philippines, Taiwan, and Thailand), Europe (Austria, Belgium, Denmark, Finland, France, Germany, Greece, Ireland, Italy, Luxembourg, Netherlands, Norway, Portugal, Spain, Sweden, and the United Kingdom), Latin America (Argentina, Brazil, Chile, Colombia, Mexico, Peru, and Venezuela), and North America (Canada and the United States). All indices are free-float adjusted by market capitalization, and are expressed in U.S. dollars. Index values are measured at closing time. The interest rates series correspond with interest rates paid on deposits for 30-day and 60 day maturities (nominal), and 90-day and 180-day maturities (inflation indexed). The sample period is 1997-2002, and the data are measured on a daily frequency. Descriptive statistics are given in Table 1.

Table 1

Descriptive Statistics

(a) Stock Indices: January 1997-December 2002

\begin{tabular}{|lr|r|r|r|}
\hline & Emerging Asia & Europe & Latin America & North America \\
\hline & & & & \\
Observations & 1,555 & 1,555 & 1,555 & 1,555 \\
Mean & -0.001 & 0.000 & 0.000 & 0.000 \\
Median & -0.001 & 0.001 & 0.000 & 0.000 \\
Std. dev. & 0.015 & 0.012 & 0.018 & 0.013 \\
25\%-quantile & -0.009 & -0.007 & -0.009 & -0.007 \\
$50 \%$-quantile & -0.001 & 0.001 & 0.000 & 0.000 \\
75\%-quantile & 0.008 & 0.007 & 0.009 & 0.007 \\
Minimum & -0.075 & -0.057 & -0.145 & -0.069 \\
Maximum & 0.076 & 0.052 & 0.131 & 0.055 \\
Skewness & 0.0 & -0.2 & -0.4 & -0.1 \\
Excess kurtosis & 4.3 & 3.3 & 74.7 & 5.3 \\
Jarque Bera test & 28.0 & 30.0 & 518.7 & 36.0 \\
P-value & 0.00 & 0.00 & 0.00 & 0.00 \\
\hline
\end{tabular}

Notes: (1) Figures are daily and measured in US dollars, and were obtained from 
Bloomberg. (2) The Latin America index includes Argentina, Brazil, Chile, Colombia, Mexico, Peru, and Venezuela; the North America index includes Canada and the United States; the Emerging Asia index includes China, India, Indonesia, Korea, Malaysia, Pakistan, Philippines, Taiwan, and Thailand; the Europe index includes Austria, Belgium, Denmark, Finland, France, Germany, Greece, Ireland, Italy, Luxembourg, Netherlands, Norway, Portugal, Spain, Sweden, and the United Kingdom; (3) The Jarque-Bera test detects whether the probability distribution of a series departures from normality.

(b) Interest Rates in Chile: January 1997-April 2002

\begin{tabular}{|lr|c|c|c|}
\hline & 30-day rate & 60-day rate & 90-day rate & 180-day rate \\
\hline Observations & 1,307 & 1,307 & 1,312 & 1,312 \\
Mean & 0.097 & 0.088 & 0.063 & 0.058 \\
Median & 0.088 & 0.083 & 0.056 & 0.056 \\
Std. Dev. & 0.042 & 0.031 & 0.027 & 0.020 \\
25\%-quantile & 0.066 & 0.064 & 0.049 & 0.048 \\
50\%-quantile & 0.088 & 0.083 & 0.056 & 0.056 \\
75\%-quantile & 0.120 & 0.109 & 0.074 & 0.067 \\
Maximum & 0.005 & 0.030 & 0.001 & 0.002 \\
Minimum & 0.370 & 0.228 & 0.219 & 0.150 \\
Skewness & 1.3 & 0.9 & 1.3 & 0.7 \\
Excess kurtosis & 11.6 & 0.7 & 21.8 & 7.4 \\
Jarque Bera test & 427.3 & 165.5 & 483.5 & 150.2 \\
P-value & 0.00 & 0.00 & 0.00 & 0.00 \\
ADF stat & -4.647 & -3.545 & -2.956 & -2.671 \\
& $(0.001)$ & $(0.035)$ & $(0.145)$ & $(0.249)$ \\
\hline
\end{tabular}

Notes: (1) The data are daily and were obtained from Bloomberg. Interest rates are annualized. (2) The lag length in the Augmented Dickey-Fuller (ADF) test statistic is determined by the Schwartz information criterion. P-values are between parentheses. (3) The Jarque-Bera test detects whether the probability distribution of a series departures from normality. 
is defined by

The energy concentration function for a vector $\mathbf{x}=\left(\mathrm{x}_{1}, \mathrm{x}_{2}, \ldots, \mathrm{x}_{\mathrm{n}}\right)^{\text {' }}$

$$
E_{x}(K)=\frac{\sum_{i=1}^{K} x_{(i)}^{2}}{\sum_{i=1}^{n} x_{i}^{2}}
$$

where $\mathrm{x}_{(\mathrm{i})}$ is the ith-largest absolute value in $\mathbf{x}$. That is, the energy in a given crystal is calculated as the sum of squares of all of its elements over the sum of squares of all observations in the original time series. One appealing characteristic of the DWT is that it is an energy preserving transform. This means that the energy in all the DWT coefficients equals the energy in the original time series.

For our data, the coefficients at the two finest scales $2^{1}$ and $2^{2}$ (i.e., d1 and d2) concentrate in all cases over 60 percent of the energy. For instance, the daily return on North America and the daily change of the 60day interest rate concentrate 76.4 and 91.1 percent of energy at scales 1 and 2, respectively. This is depicted in Figure 1,where we present a multi-resolution decomposition for each series.(Computations were carried out with $\mathrm{S}+$ Wavelets 2.0). At each scale, the corresponding component is constructed according to equations (7a) and (7b). Most short-term fluctuations are observed in recomposed crystals D1and D2, and some in the third (i.e., 8-day horizon). Meanwhile, medium-term fluctuations are captured at the coarser scales (i.e., within 16 and 64 days). 
Figure 1 Multi-resolution Decomposition

(a) Stock Index Returns

Emarging Asia

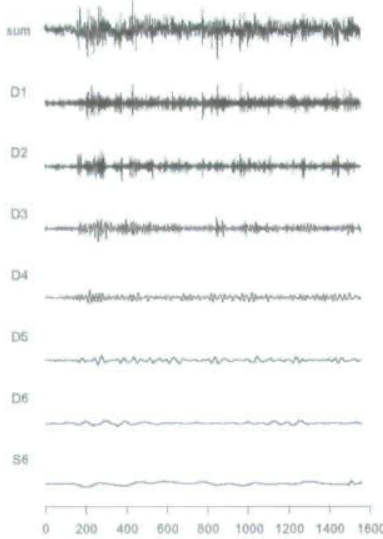

Latin America

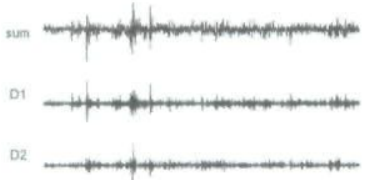

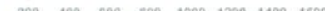

Europe

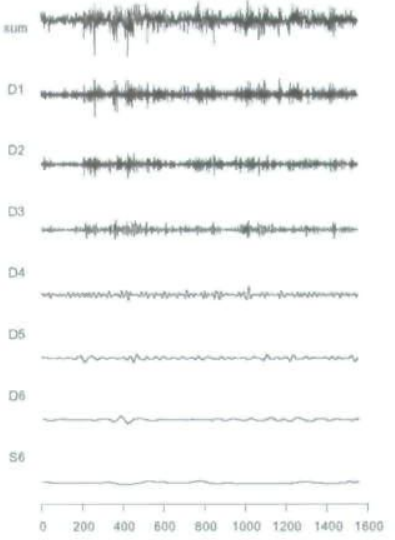

North Americai

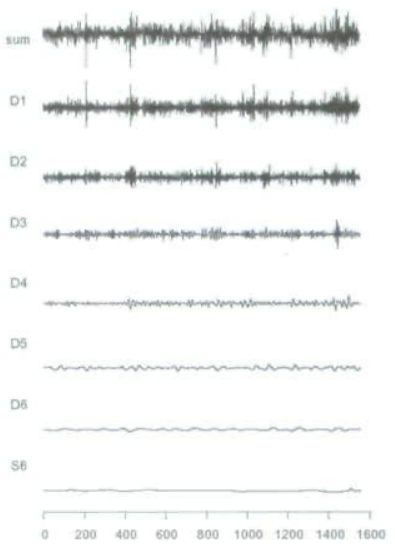


(b) Daily change in interest rates

30-day interest rate

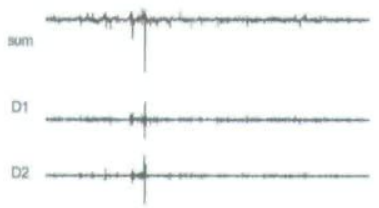

D3

D5

S6

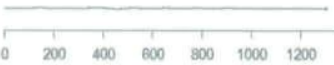

90-day interest rate

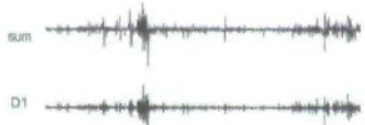

D2

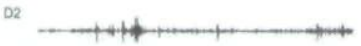

D3

04

D5

D6

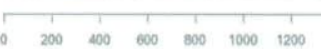

60-day interest rate

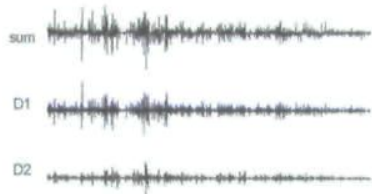

03

D4

D5

$\$ 6$

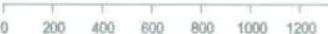

180-day interest rate

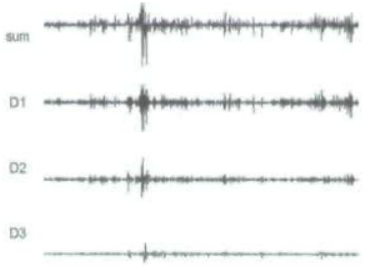

D4

D.

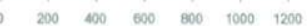

Note: The wavelet function used in all cases is a symmmlet, $\mathrm{s} 8$. The number is related to the width and smoothness of the wavelet function. (See Bruce and Gao, 1996).. 


\section{B. Breakpoints in Volatility}

In this section, we focus on detecting permanent shifts in volatility.We compare wavelet analysis with Inclan and Tiao (1994)'s Iterative Cumulative Sum of Squares (ICSS) algorithm. For the stock indices, we concentrate on two global events: the outbreak of the Asian crisis in 1997 and the terrorist attacks of September 11, 2001. For Chile's interest rates, we concentrate on a domestic event triggered by a change in monetary policy conduction in August 2001.Specifically, the sharp decrease in inflation over the last decade-from 26 percent in 1990 to 4 percent in 2001-led the Central Bank of Chile to switched its monetary policy interest rate from an inflation-indexed to a nominal target.

There is evidence in the literature that the ICSS algorithm tends to overestimate the number of breakpoints, due to the fact that the assumption of independence in time-series data is usually violated. In particular, Bacmann and Dubois (2002) point out that the behavior of the ICSS algorithm is questionable under the presence of conditional heteroskedasticity. They show that one way to circumvent this problem is by filtering the return series by a GARCH $(1,1)$ model, and applying the ICSS algorithm to the standardized residuals. By applying this procedure (and an alternative one they propose) to stock market indexes in ten emerging markets, Bacmann and Dubois obtain results that differ to great extent from those in Aggarwal, Inclan and Leal (1999). They conclude that structural breaks in unconditional variance are less frequent than it was shown previously.

Based on this evidence, we test for volatility shifts before and after filtering the data for conditional heteroskedascity and serial correlation. As shown below, the number of shifts detected by the ICSS algorithm and wavelets methods is substantially reduced when the data is filtered.

The next two sections briefly describe the wavelet variance analysis and the ICSS algorithm.

a. Wavelet Variance Analysis

Wavelet variance analysis consists in partitioning the variance of a time series into pieces that are associated to different time scales. It tells us what scales are important contributors to the overall variability of a series (see Percival 
and Walden, 2000). In particular, let $x_{1}, x_{2}, \ldots, x_{n}$ be a time series of interest, which is assumed to be a realization of a stationary process with variance $\sigma_{X}^{2}$. If $v_{X}^{2}\left(\tau_{j}\right)$ denotes the wavelet variance for scale $\tau_{j} \equiv 2^{j-1}$, then the following relationship holds:

$$
\sigma_{\mathrm{x}}^{2}=\sum_{\mathrm{j}=1}^{\infty} v_{\mathrm{x}}^{2}\left(\tau_{\mathrm{j}}\right)
$$

This relationship is analogous to that between the variance of a stationary process and its spectral density function (SDF):

$$
\sigma_{X}^{2}=\int_{-1 / 2}^{1 / 2} S_{X}(f) d f
$$

where $S_{x}(f)$ is the SDF at the frequency $f \in[-1 / 2,1 / 2]$.

The SDF for a stationary process decomposes the variance across different frequencies, whereas the wavelet variance decomposes it across different scales. Given that the scale $\tau_{j}$ can be related to range of frequencies in the interval $\left[1 / 2^{\mathrm{j}}, 1 / 2^{\mathrm{j}-1}\right]$, the wavelet variance usually leads to a more succinct decomposition. Moreover, unlike the SDF, the square root of the wavelet variance is expressed in the same units as the original data.

Another advantage of the wavelet variance is that it replaces the sample variance with a sequence of variances over given scales. That is, it offers a scale-by-scale decomposition of variability, which makes it possible to analyze a process that exhibits fluctuations over a range of different scales.

Let $\mathrm{n}_{\mathrm{j}}^{\prime}=\mathrm{n} / 2^{\mathrm{j}}$ be the number of discrete wavelet transform (DWT) coefficients at level $\mathrm{j}$, where $\mathrm{n}$ is the sample size, and $\mathrm{L}_{\mathrm{j}}^{\prime} \equiv(\mathrm{L}-2)\left(1-2^{-\mathrm{j}}\right)$ be the number of DWT boundary coefficients ${ }^{3}$ at level j (provided that $\mathrm{n}_{\mathrm{j}}^{\prime}>\mathrm{L}_{\mathrm{j}}^{\prime}$ ), where $\mathrm{L}$ is the width of the wavelet filter $\mathrm{r}^{4}$. An unbiased estimator of the wavelet variance is defined as

$$
\hat{v}_{x}^{2}\left(\tau_{j}\right) \equiv \frac{1}{\left(n_{j}^{\prime}-L_{j}^{\prime}\right) 2^{j}} \sum_{t=L_{j}^{\prime}-1}^{n_{j}^{\prime}-1} d_{j, t}^{2}
$$

Given that the DWT decorrelates the data, the non-boundary wavelet coefficients in a given level $\left(\mathbf{d}_{\mathrm{j}}\right)$ are zero-mean Gaussian white noise process. 
For a homogeneous distribution of $\mathrm{d}_{\mathrm{j}, \mathrm{t}}$, there is an expected linear increase in the cumulative energy as a function of time. The so-called D-statistic denotes the maximum deviation of $\mathrm{d}_{1, \mathrm{t}}$ from a hypothetical linear cumulative energy trend. The D-statistic is compared to the critical value of the distribution of D, for a given significance level, under the null hypothesis of variance homogeneity.

\section{b. The ICSS Algorithm}

The idea behind the Inclan and Tiao's ICSS algorithm can be summarized as follows. A time series of interest has a stationary unconditional variance over an initial time period until a sudden break takes place. The unconditional variance is then stationary until the next sudden change occurs. This process repeats through time, giving a time series of observations with a number of M breakpoints in the unconditional variance in $\mathrm{n}$ observations:

$$
\sigma_{\mathrm{t}}^{2}=\left\{\begin{array}{cc}
\tau_{0}^{2} & 1<\mathrm{t}<\mathrm{l}_{1} \\
\tau_{1}^{2} & \mathrm{l}_{1}<\mathrm{t}<\mathrm{l}_{2} \\
& \cdots . \\
\tau_{\mathrm{M}}^{2} & \mathrm{l}_{\mathrm{M}}<\mathrm{t}<\mathrm{n}
\end{array}\right.
$$

\footnotetext{
${ }^{3}$ Boundary coefficients are those that are formed by combining together some values from the beginning of the sequence of scaling coefficients with some values from the end.

${ }^{4}$ In practical applications, we deal with sequences of values (i.e., time series) rather than functions defined over the entire real axis. Therefore, instead of using actual wavelets, we work with short sequences of values named wavelet filters. The number of values in the sequence is called the width of the wavelet filter, and it is denoted by L.
} 
In order to estimate the number of changes and the point in time of variance shifts, acumulative sum of square residuals is used, $\mathrm{C}_{\mathrm{k}}=\sum_{\mathrm{t}=1}^{\mathrm{k}} \varepsilon_{\mathrm{t}}^{2}{ }^{\prime} \mathrm{k}=1,2, \ldots, \mathrm{n}$, where $\left\{\varepsilon_{\mathrm{t}}\right\}$ is a series of uncorrelated random variables with zero mean and unconditional variance $\sigma_{t}^{2}$, as in (12). Inclan and Tiao define the statistic:

$\mathrm{D}_{\mathrm{k}}=\frac{\mathrm{C}_{\mathrm{k}}}{\mathrm{C}_{\mathrm{n}}}-\frac{\mathrm{k}}{\mathrm{n}} \quad \mathrm{k}=1,2, \ldots, \mathrm{n}, \quad \mathrm{D}_{0}=\mathrm{D}_{\mathrm{n}}=0$.

If there are no changes in variance over the whole sample period, $D_{k}$ will oscillate around zero. Otherwise, if there are one or more shifts in variance, $D_{k}$ will departure from zero. The ICSS algorithm systematically looks for breaks in variance at different points in the series. A full description of the algorithm is given in Inclan and Tiao's paper.

\section{c. The Two Approaches Compared}

We first applied the ICSS algorithm to the four stock returns series over 1997-2002, and to the interest rates series over 2000-April 2002. Figures 2 and 3 show the evolution of each return series (first difference, in the case of interest rates) along with \pm 3 standard deviations. A discontinuity in the dotted lines indicates the presence of a volatility breakpoint. 
Figure 2

Structural Breaks in Volatility detected by the ICSS algorithm: 1997-2002 (a) Emerging Asia

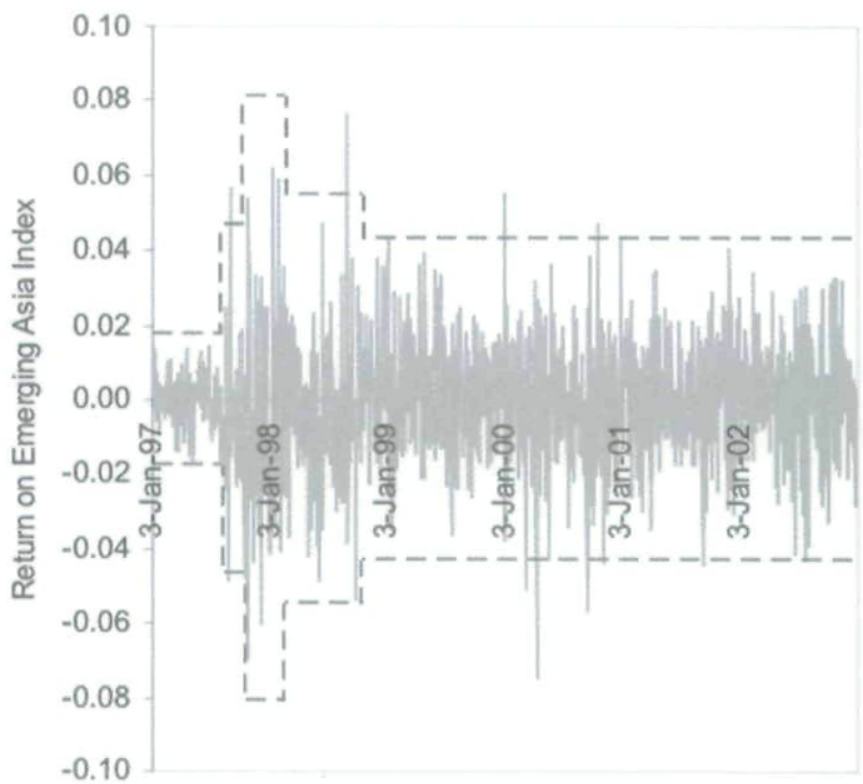

(b) Europe

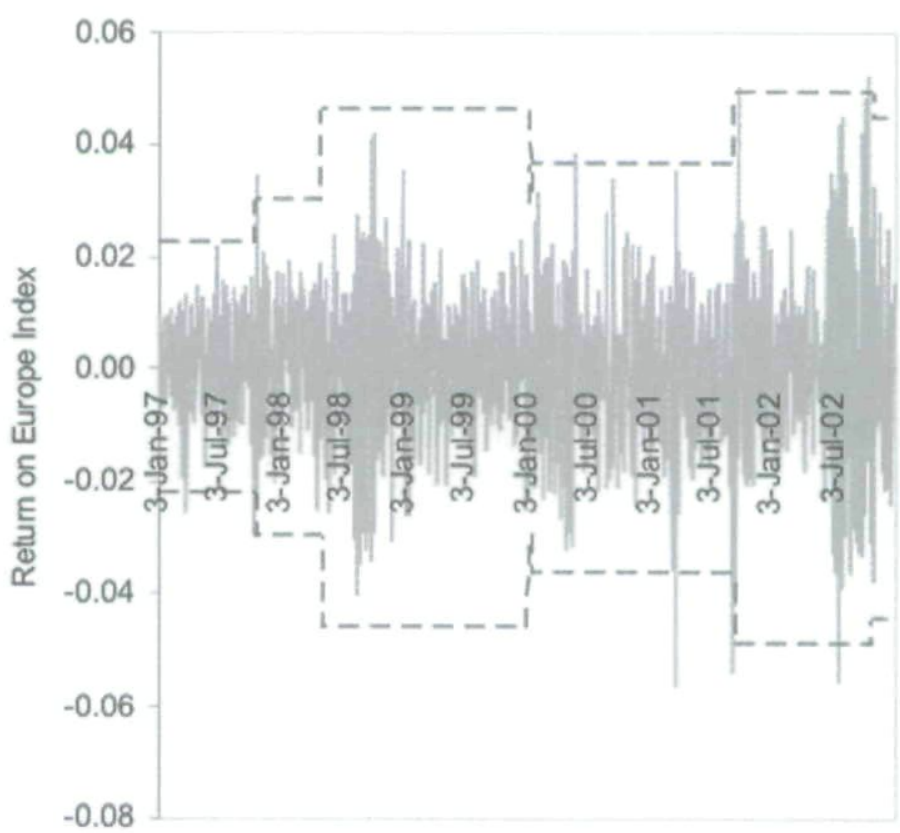


(c) Latin America

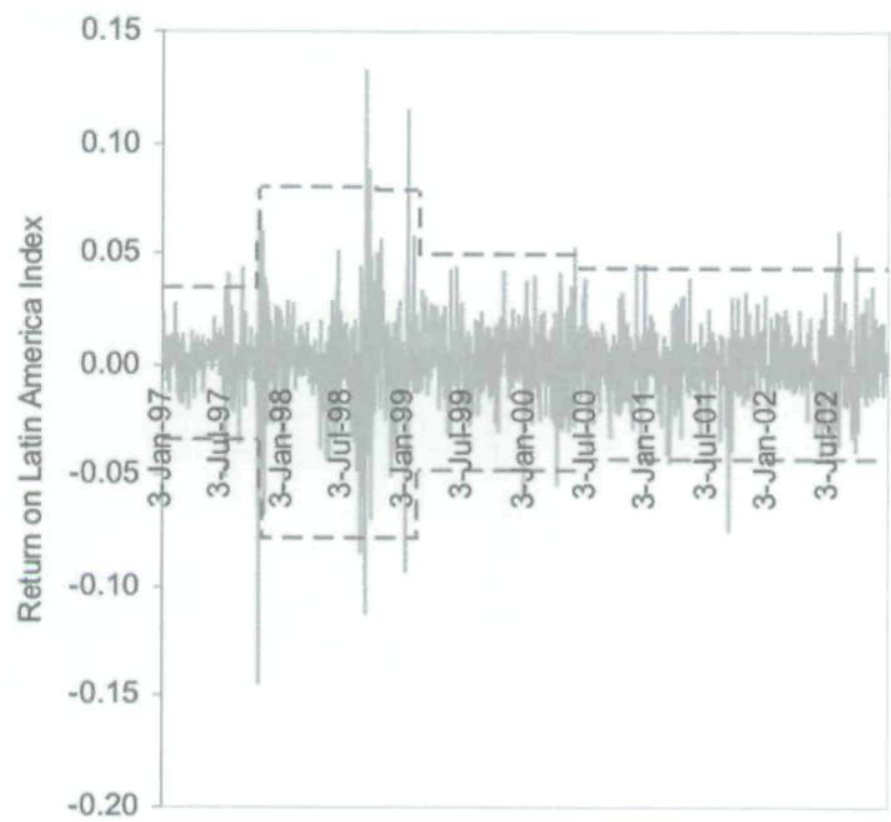

(d) North America

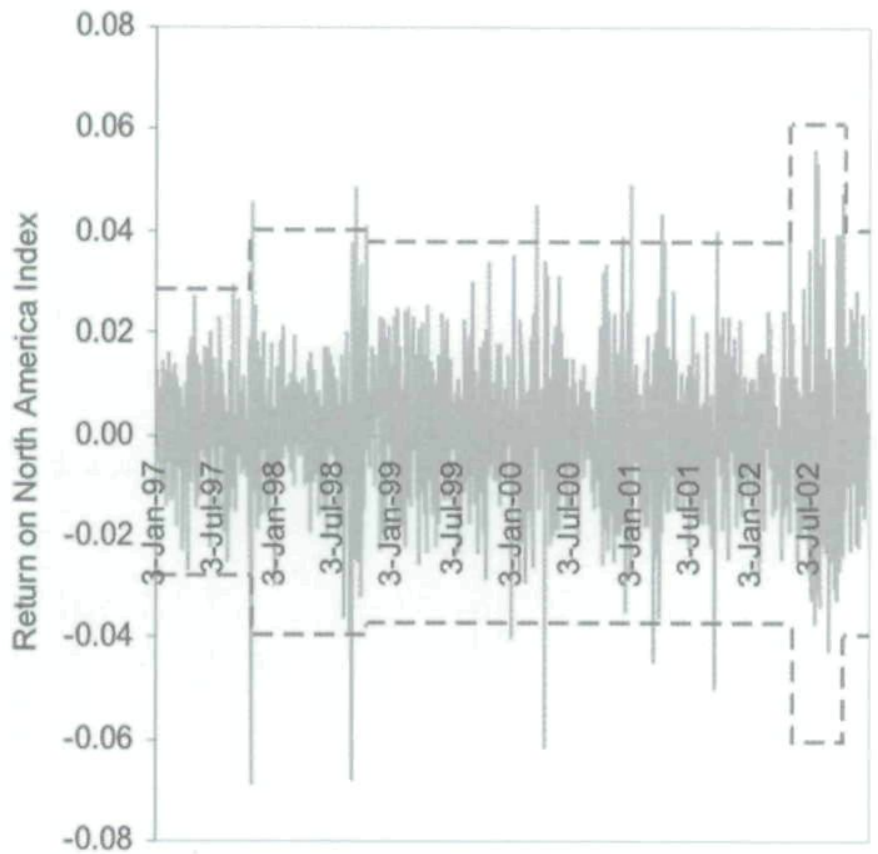

Notes: Dotted lines represent \pm 3 standard deviations. 
Figure 3

ICSS Algorithm and Structural Breaks in Volatility of Interest Rates in Chile: January 2000-April 2002

(a)

30-day deposit rate

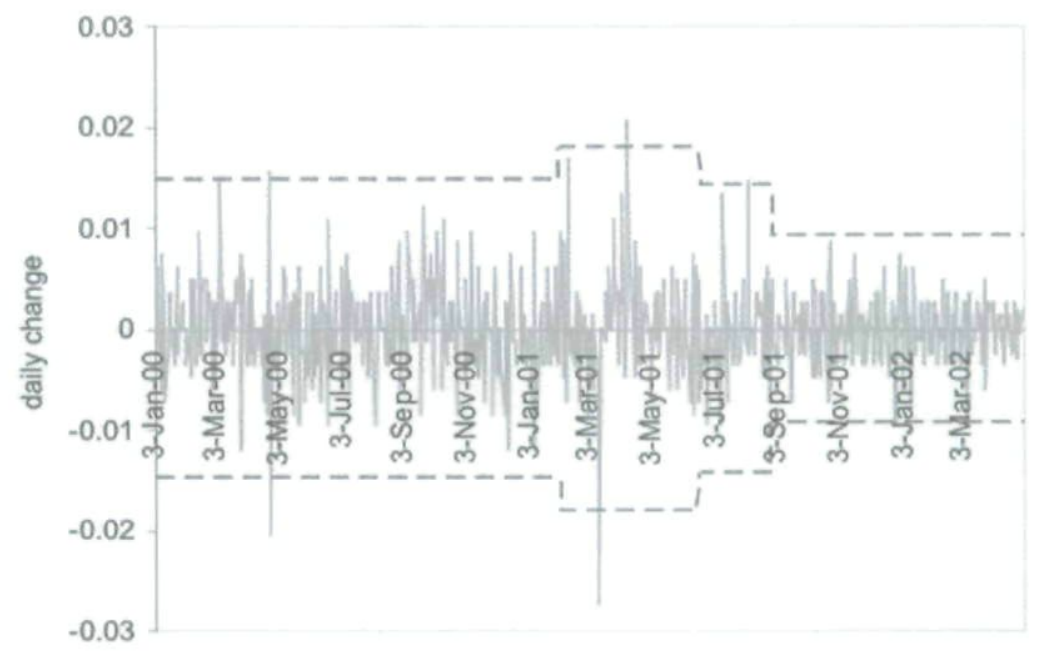

(b)

60-day deposit rate

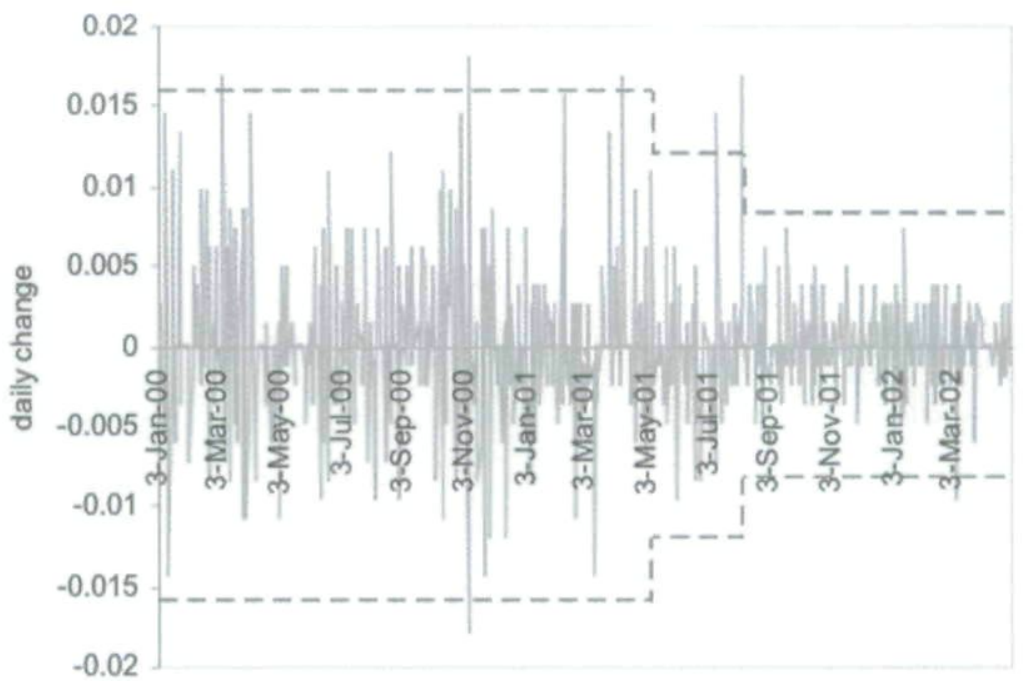


(c)

90-day deposit rate

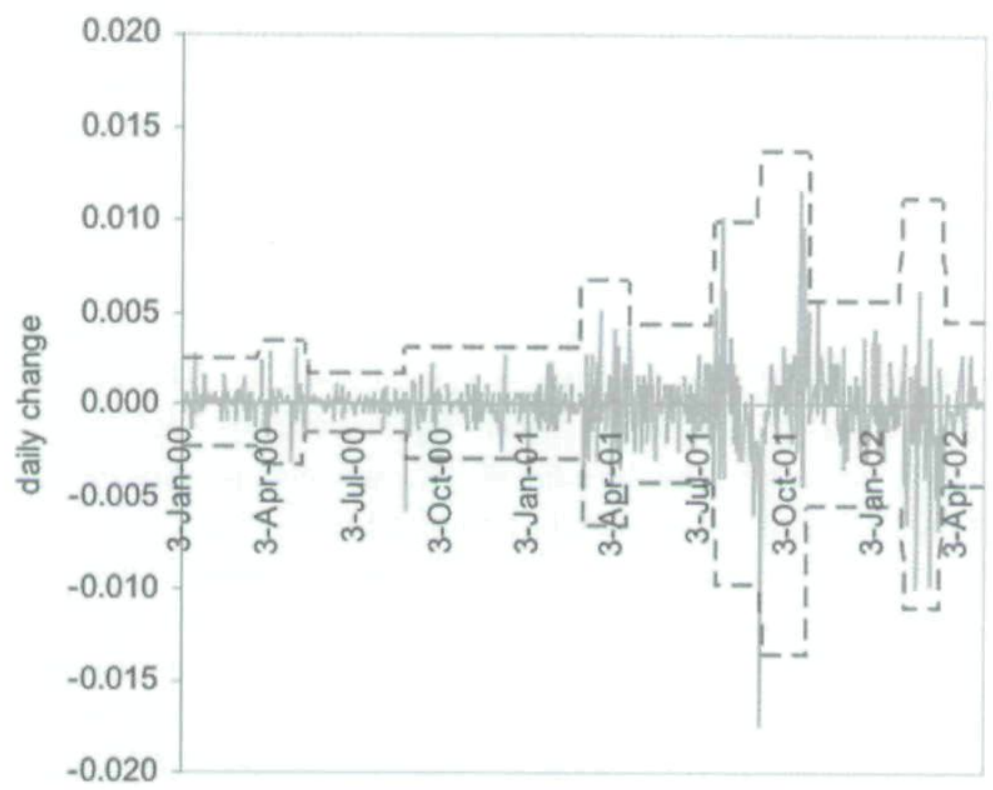

(d)

180-day deposit rate

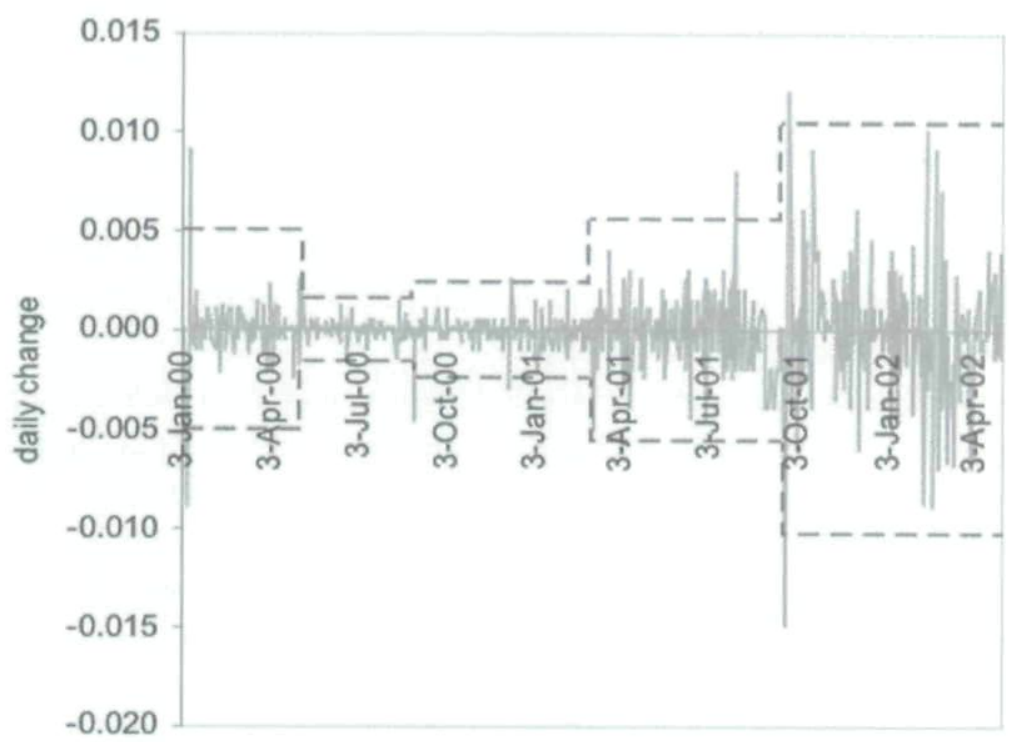

Note: The data are daily and were obtained from Bloomberg. 
For Emerging Asia, the ICSS algorithm detects breakpoints in August 1997, October 1997, February 1998, and October 1998. For Latin America, breakpoints are found for October 1997, October 1998, February 1999, and June 2000. For North America, breakpoints took place in October 1997, October 1998, May 2002, and October 2002. Finally, for Europe, breakpoints are found in October 1997, April 1998, October 1998, January 2000, September 2001, and October 2002. Only in this latter case, does the ICSS algorithm detect a permanent shift in volatility around September 11,2001.

For interest rates, the ICSS algorithm detects breakpoints in variance in the 30-day series in February 2001, June 2001, and August 2001; in May 2001 and August 2001 for the 60-day series; in March 2000, May 2000, August 2000, March 2001, April 2001, July 2001, September 2001, October 2001, February 2002, and March 2002 for the 90-day rate; and, in May 2000, August 2000, March 2001, and September 2001 for the 180-day rate.

In order to compare the ICSS algorithm with wavelet analysis, we took as a benchmark the dates of breakpoints detected by the ICSS algorithm, and tested whether wavelet analysis also found breakpoints around the same time periods. In particular, for the stock indices, we focused on 1997-1998, 19992000, and 2001-2002. For interest rates, we concentrated on 2000-1/2001 and 2/2001-4/2002. Tables 2 and 3 present our results.

In the case of Emerging Asia, both procedures detect volatility shifts during 1997-1998, but none in 1999-2002. In particular, the wavelet variance test finds breakpoints over 1997-1998 at the finest scales (d1, d2, and d3) but not at the coarser ones (d4, d5, and d6). For North America, the ICSS fails to detect breakpoints between 1999 and 2001, whereas wavelet analysis finds some evidence against the null hypothesis of variance homogeneity in that period-in, particular at scales 1 and 6. For 1999-2002, the evidence against the null hypothesis is mixed, according to wavelet analysis: breakpoints are detected at scale 1 at all significance levels, and at scales 2 and 3 at the 10 percent and 5 percent of significance level, respectively.

Finally, for Europe, for 1997-1998, both tests find evidence against the null hypothesis. However, unlike the ICSS algorithm, the wavelet variance test does not find any breakpoints in 2000. Regarding 2001, the latter test finds shifts only at scale 1 at all significance levels, and at the 10 percent level at scale 2. No breakpoints are found at higher scales of the data. When taking 2001-2002, the null hypothesis of homogeneity is rejected, at all significance levels, at scales 1,2, and 3. This suggests that the extra year of data (2002) adds some variance instability, as detected by the ICSS algorithm. 
Table 2

Volatility shifts test at different time scales: Stock indices

(a) Emerging Asia

\begin{tabular}{|r|c|c|ccc|cccc|}
\hline Period & Scale & D-statistic & \multicolumn{3}{|c|}{ Critical Values } & \multicolumn{3}{c|}{$\mathrm{H}_{0}$ : Homogeneity } \\
& & & $10 \%$ & $5 \%$ & $1 \%$ & $10 \%$ & $5 \%$ & $1 \%$ \\
\hline \multirow{2}{*}{$1997-1998$} & & d1 & 0.308 & 0.108 & 0.120 & 0.144 & $\mathrm{~F}$ & $\mathrm{~F}$ & $\mathrm{~F}$ \\
& $\mathrm{~d} 2$ & 0.283 & 0.151 & 0.167 & 0.202 & $\mathrm{~F}$ & $\mathrm{~F}$ & $\mathrm{~F}$ \\
& $\mathrm{~d} 3$ & 0.290 & 0.218 & 0.243 & 0.295 & $\mathrm{~F}$ & $\mathrm{~F}$ & $\mathrm{~F}$ \\
& $\mathrm{~d} 4$ & 0.274 & 0.319 & 0.355 & 0.428 & $\mathrm{~T}$ & $\mathrm{~T}$ & $\mathrm{~T}$ \\
& $\mathrm{~d} 5$ & 0.375 & 0.503 & 0.558 & 0.659 & $\mathrm{~T}$ & $\mathrm{~T}$ & $\mathrm{~T}$ \\
& $\mathrm{~d} 6$ & 0.702 & 0.993 & 0.998 & 0.999 & $\mathrm{~T}$ & $\mathrm{~T}$ & $\mathrm{~T}$ \\
& $\mathrm{~d} 1$ & 0.055 & 0.077 & 0.085 & 0.101 & $\mathrm{~T}$ & $\mathrm{~T}$ & $\mathrm{~T}$ \\
& $\mathrm{~d} 2$ & 0.087 & 0.109 & 0.121 & 0.144 & $\mathrm{~T}$ & $\mathrm{~T}$ & $\mathrm{~T}$ \\
& $\mathrm{~d} 3$ & 0.088 & 0.152 & 0.168 & 0.203 & $\mathrm{~T}$ & $\mathrm{~T}$ & $\mathrm{~T}$ \\
& $\mathrm{~d} 4$ & 0.127 & 0.218 & 0.243 & 0.295 & $\mathrm{~T}$ & $\mathrm{~T}$ & $\mathrm{~T}$ \\
& $\mathrm{~d} 5$ & 0.266 & 0.319 & 0.355 & 0.428 & $\mathrm{~T}$ & $\mathrm{~T}$ & $\mathrm{~T}$ \\
& $\mathrm{~d} 6$ & 0.459 & 0.503 & 0.558 & 0.659 & $\mathrm{~T}$ & $\mathrm{~T}$ & $\mathrm{~T}$ \\
\hline
\end{tabular}

Note:An Inclan-Tiao approximation is used to compute the critical values for sample sizes $\mathrm{N} \geq 128$, while a Monte Carlo Technique is used for $\mathrm{N}<128$. " $\mathrm{T}$ " indicates that we cannot reject the null hypothesis and "F" otherwise. 
(b) Europe

\begin{tabular}{|c|c|c|c|c|c|c|c|c|}
\hline \multirow[t]{2}{*}{ Period } & \multirow[t]{2}{*}{ Scale } & \multirow[t]{2}{*}{ D-statistic } & \multicolumn{3}{|c|}{ Critical Values } & \multicolumn{3}{|c|}{$\mathrm{H}_{0}$ : Homogeneity } \\
\hline & & & $10 \%$ & $5 \%$ & $1 \%$ & $10 \%$ & $5 \%$ & $1 \%$ \\
\hline \multirow[t]{6}{*}{ 1997-1998 } & dl & 0.234 & 0.108 & 0.120 & 0.144 & $\mathrm{~F}$ & $\mathrm{~F}$ & $\mathrm{~F}$ \\
\hline & $\mathrm{d} 2$ & 0.422 & 0.151 & 0.167 & 0.202 & $\mathrm{~F}$ & $\mathrm{~F}$ & $\mathrm{~F}$ \\
\hline & d3 & 0.218 & 0.218 & 0.243 & 0.295 & $\mathrm{~T}$ & $\mathrm{~T}$ & $\mathrm{~T}$ \\
\hline & $\mathrm{d} 4$ & 0.479 & 0.319 & 0.355 & 0.428 & $\mathrm{~F}$ & $\mathrm{~F}$ & $\mathrm{~F}$ \\
\hline & d5 & 0.328 & 0.503 & 0.558 & 0.659 & $\mathrm{~T}$ & $\mathrm{~T}$ & $\mathrm{~T}$ \\
\hline & d6 & 0.767 & 0.993 & 0.998 & 0.999 & $\mathrm{~T}$ & $\mathrm{~T}$ & $\mathrm{~T}$ \\
\hline \multirow[t]{5}{*}{$1999-2000$} & d1 & 0.074 & 0.149 & 0.167 & 0.200 & $\mathrm{~T}$ & $\mathrm{~T}$ & $\mathrm{~T}$ \\
\hline & d2 & 0.154 & 0.214 & 0.239 & 0.290 & $\mathrm{~T}$ & $\mathrm{~T}$ & $\mathrm{~T}$ \\
\hline & d3 & 0.138 & 0.319 & 0.355 & 0.428 & $\mathrm{~T}$ & $\mathrm{~T}$ & $\mathrm{~T}$ \\
\hline & d4 & 0.419 & 0.503 & 0.558 & 0.659 & $\mathrm{~T}$ & $\mathrm{~T}$ & $\mathrm{~T}$ \\
\hline & d5 & 0.617 & 0.993 & 0.998 & 0.999 & $\mathrm{~T}$ & $\mathrm{~T}$ & $\mathrm{~T}$ \\
\hline \multirow[t]{6}{*}{2001} & dl & 0.151 & 0.108 & 0.120 & 0.144 & $\mathrm{~F}$ & $\mathrm{~F}$ & $\mathrm{~F}$ \\
\hline & $\mathrm{d} 2$ & 0.167 & 0.151 & 0.167 & 0.202 & $\mathrm{~F}$ & $\mathrm{~T}$ & $\mathrm{~T}$ \\
\hline & $\mathrm{d} 3$ & 0.171 & 0.218 & 0.243 & 0.295 & $\mathrm{~T}$ & $\mathrm{~T}$ & $\mathrm{~T}$ \\
\hline & d4 & 0.274 & 0.319 & 0.355 & 0.428 & $\mathrm{~T}$ & $\mathrm{~T}$ & $\mathrm{~T}$ \\
\hline & d5 & 0.182 & 0.503 & 0.558 & 0.659 & $\mathrm{~T}$ & $\mathrm{~T}$ & $\mathrm{~T}$ \\
\hline & d6 & 0.966 & 0.993 & 0.998 & 0.999 & $\mathrm{~T}$ & $\mathrm{~T}$ & $\mathrm{~T}$ \\
\hline \multirow[t]{5}{*}{ 2001-2002 } & dl & 0.328 & 0.149 & 0.167 & 0.200 & $\mathrm{~F}$ & $\mathrm{~F}$ & $\mathrm{~F}$ \\
\hline & d2 & 0.356 & 0.214 & 0.239 & 0.290 & $\mathrm{~F}$ & $\mathrm{~F}$ & $\mathrm{~F}$ \\
\hline & $\mathrm{d} 3$ & 0.433 & 0.319 & 0.355 & 0.428 & $\mathrm{~F}$ & $\mathrm{~F}$ & $\mathrm{~F}$ \\
\hline & d4 & 0.433 & 0.503 & 0.558 & 0.659 & $\mathrm{~T}$ & $\mathrm{~T}$ & $\mathrm{~T}$ \\
\hline & d5 & 0.727 & 0.993 & 0.998 & 0.999 & $\mathrm{~T}$ & $\mathrm{~T}$ & $\mathrm{~T}$ \\
\hline
\end{tabular}

Note: An Inclan-Tiao approximation is used to compute the critical values for sample sizes $\mathrm{N} \geq 128$, while a Monte Carlo Technique is used for $\mathrm{N}<128$. " $\mathrm{T}$ " indicates that we cannot reject the null hypothesis and "F" otherwise. 
(c) Latin America

\begin{tabular}{|c|c|c|ccc|ccc|}
\hline Period & Scale & D-statistic & \multicolumn{3}{|c|}{ Critical Values } & \multicolumn{3}{c|}{$\mathrm{H}_{0}$ : Homogeneity } \\
& & & $10 \%$ & $5 \%$ & $1 \%$ & $10 \%$ & $5 \%$ & $1 \%$ \\
\hline \multirow{2}{*}{$1997-1998$} & \multirow{2}{*}{ d1 } & 0.109 & 0.108 & 0.120 & 0.144 & $\mathrm{~F}$ & $\mathrm{~T}$ & $\mathrm{~T}$ \\
& $\mathrm{~d} 2$ & 0.155 & 0.151 & 0.167 & 0.202 & $\mathrm{~F}$ & $\mathrm{~T}$ & $\mathrm{~T}$ \\
& $\mathrm{~d} 3$ & 0.198 & 0.218 & 0.243 & 0.295 & $\mathrm{~T}$ & $\mathrm{~T}$ & $\mathrm{~T}$ \\
& $\mathrm{~d} 4$ & 0.164 & 0.319 & 0.355 & 0.428 & $\mathrm{~T}$ & $\mathrm{~T}$ & $\mathrm{~T}$ \\
& $\mathrm{~d} 5$ & 0.545 & 0.503 & 0.558 & 0.659 & $\mathrm{~F}$ & $\mathrm{~T}$ & $\mathrm{~T}$ \\
& $\mathrm{~d} 6$ & 0.998 & 0.993 & 0.998 & 0.999 & $\mathrm{~F}$ & $\mathrm{~T}$ & $\mathrm{~T}$ \\
& $\mathrm{~d} 1$ & 0.070 & 0.088 & 0.098 & 0.117 & $\mathrm{~T}$ & $\mathrm{~T}$ & $\mathrm{~T}$ \\
& $\mathrm{~d} 2$ & 0.092 & 0.126 & 0.140 & 0.167 & $\mathrm{~T}$ & $\mathrm{~T}$ & $\mathrm{~T}$ \\
& $\mathrm{~d} 3$ & 0.115 & 0.176 & 0.195 & 0.232 & $\mathrm{~T}$ & $\mathrm{~T}$ & $\mathrm{~T}$ \\
& $\mathrm{~d} 4$ & 0.162 & 0.256 & 0.284 & 0.342 & $\mathrm{~T}$ & $\mathrm{~T}$ & $\mathrm{~T}$ \\
& $\mathrm{~d} 5$ & 0.328 & 0.381 & 0.425 & 0.505 & $\mathrm{~T}$ & $\mathrm{~T}$ & $\mathrm{~T}$ \\
& $\mathrm{~d} 6$ & 0.475 & 0.636 & 0.703 & 0.815 & $\mathrm{~T}$ & $\mathrm{~T}$ & $\mathrm{~T}$ \\
\hline \multirow{5}{*}{$1999-2002$} & $\mathrm{~d} 1$ & 0.052 & 0.077 & 0.085 & 0.101 & $\mathrm{~T}$ & $\mathrm{~T}$ & $\mathrm{~T}$ \\
& $\mathrm{~d} 2$ & 0.088 & 0.109 & 0.121 & 0.144 & $\mathrm{~T}$ & $\mathrm{~T}$ & $\mathrm{~T}$ \\
& $\mathrm{~d} 3$ & 0.116 & 0.152 & 0.168 & 0.203 & $\mathrm{~T}$ & $\mathrm{~T}$ & $\mathrm{~T}$ \\
& $\mathrm{~d} 4$ & 0.114 & 0.218 & 0.243 & 0.295 & $\mathrm{~T}$ & $\mathrm{~T}$ & $\mathrm{~T}$ \\
& $\mathrm{~d} 5$ & 0.213 & 0.319 & 0.355 & 0.428 & $\mathrm{~T}$ & $\mathrm{~T}$ & $\mathrm{~T}$ \\
& $\mathrm{~d} 6$ & 0.232 & 0.503 & 0.558 & 0.659 & $\mathrm{~T}$ & $\mathrm{~T}$ & $\mathrm{~T}$ \\
\hline
\end{tabular}

Note: An Inclan-Tiao approximation is used to compute the critical values for sample sizes $\mathrm{N} \geq 128$, while a Monte Carlo Technique is used for $\mathrm{N}<128$. " $\mathrm{T}$ " indicates that we cannot reject the null hypothesis and "F" otherwise. 
(d) North America

\begin{tabular}{|r|c|c|ccc|ccc|}
\hline Period & Scale & D-statistic & \multicolumn{3}{|c|}{ Critical Values } & \multicolumn{3}{|c|}{$\mathrm{H}_{0}$ : Homogeneity } \\
& & & $10 \%$ & $5 \%$ & $1 \%$ & $10 \%$ & $5 \%$ & $1 \%$ \\
\hline \multirow{2}{*}{ 1997-1998 } & \multirow{2}{*}{ d1 } & 0.103 & 0.108 & 0.120 & 0.144 & $\mathrm{~T}$ & $\mathrm{~T}$ & $\mathrm{~T}$ \\
& $\mathrm{~d} 2$ & 0.066 & 0.151 & 0.167 & 0.202 & $\mathrm{~T}$ & $\mathrm{~T}$ & $\mathrm{~T}$ \\
& $\mathrm{~d} 3$ & 0.092 & 0.218 & 0.243 & 0.295 & $\mathrm{~T}$ & $\mathrm{~T}$ & $\mathrm{~T}$ \\
& $\mathrm{~d} 4$ & 0.391 & 0.319 & 0.355 & 0.428 & $\mathrm{~F}$ & $\mathrm{~F}$ & $\mathrm{~T}$ \\
& $\mathrm{~d} 5$ & 0.316 & 0.503 & 0.558 & 0.659 & $\mathrm{~T}$ & $\mathrm{~T}$ & $\mathrm{~T}$ \\
& $\mathrm{~d} 6$ & 0.984 & 0.993 & 0.998 & 0.999 & $\mathrm{~T}$ & $\mathrm{~T}$ & $\mathrm{~T}$ \\
\hline \multirow{5}{*}{$1999-2001$} & $\mathrm{~d} 1$ & 0.056 & 0.088 & 0.098 & 0.117 & $\mathrm{~T}$ & $\mathrm{~T}$ & $\mathrm{~T}$ \\
& $\mathrm{~d} 2$ & 0.120 & 0.126 & 0.140 & 0.167 & $\mathrm{~T}$ & $\mathrm{~T}$ & $\mathrm{~T}$ \\
& $\mathrm{~d} 3$ & 0.125 & 0.176 & 0.195 & 0.232 & $\mathrm{~T}$ & $\mathrm{~T}$ & $\mathrm{~T}$ \\
& $\mathrm{~d} 4$ & 0.131 & 0.256 & 0.284 & 0.342 & $\mathrm{~T}$ & $\mathrm{~T}$ & $\mathrm{~T}$ \\
& $\mathrm{~d} 5$ & 0.232 & 0.381 & 0.425 & 0.505 & $\mathrm{~T}$ & $\mathrm{~T}$ & $\mathrm{~T}$ \\
& $\mathrm{~d} 6$ & 0.598 & 0.636 & 0.703 & 0.815 & $\mathrm{~T}$ & $\mathrm{~T}$ & $\mathrm{~T}$ \\
& $\mathrm{~d} 1$ & 0.058 & 0.077 & 0.085 & 0.101 & $\mathrm{~T}$ & $\mathrm{~T}$ & $\mathrm{~T}$ \\
& $\mathrm{~d} 2$ & 0.0944 & 0.109 & 0.121 & 0.144 & $\mathrm{~T}$ & $\mathrm{~T}$ & $\mathrm{~T}$ \\
& $\mathrm{~d} 3$ & 0.088 & 0.152 & 0.168 & 0.203 & $\mathrm{~T}$ & $\mathrm{~T}$ & $\mathrm{~T}$ \\
& $\mathrm{~d} 4$ & 0.169 & 0.218 & 0.243 & 0.295 & $\mathrm{~T}$ & $\mathrm{~T}$ & $\mathrm{~T}$ \\
& $\mathrm{~d} 5$ & 0.166 & 0.319 & 0.355 & 0.428 & $\mathrm{~T}$ & $\mathrm{~T}$ & $\mathrm{~T}$ \\
& $\mathrm{~d} 6$ & 0.295 & 0.503 & 0.558 & 0.659 & $\mathrm{~T}$ & $\mathrm{~T}$ & $\mathrm{~T}$ \\
\hline
\end{tabular}

Note: An Inclan-Tiao approximation is used to compute the critical values for sample sizes $\mathrm{N} \geq 128$, while a Monte Carlo Technique is used for $\mathrm{N}<128$. " $\mathrm{T}$ " indicates that we cannot reject the null hypothesis and "F" otherwise. 
Regarding interest rates, wavelet analysis finds breakpoints in both periods for the 30-day, 90-day, and 180-day interest rates, but none for the 60day interest rate in the first period. In general, most violations of variance homogeneity are observed in the second period, in which the change in monetary policy occurred. For instance, variance homogeneity is rejected at all significance levels at the first four scales of the 30-day interest rate, and at the first three scales of the 60-day interest rate. Overall, the periods of breakpoints coincide with those detected by the ICSS algorithm. The exception is the 30-day interest rate series, for which the ICSS algorithm does not find any shifts in variance prior to February 2001.

Table 3

Volatility shifts test at different time scales: Interest rates on deposits

(a) 30 days

\begin{tabular}{|c|c|c|ccc|cccc|}
\hline Period & Scale & P-statistic & \multicolumn{3}{|c|}{ Critical Values } & \multicolumn{3}{c|}{$\mathrm{H}_{0}$ : Homogeneity } \\
& & & $10 \%$ & $5 \%$ & $1 \%$ & $10 \%$ & $5 \%$ & $1 \%$ \\
\hline \multirow{2}{*}{ 2000-Jan 2001 } & d1 & 0.099 & 0.152 & 0.169 & 0.203 & $\mathrm{~T}$ & $\mathrm{~T}$ & $\mathrm{~T}$ \\
& $\mathrm{~d} 2$ & 0.242 & 0.213 & 0.236 & 0.287 & $\mathrm{~F}$ & $\mathrm{~F}$ & $\mathrm{~T}$ \\
& $\mathrm{~d} 3$ & 0.191 & 0.315 & 0.351 & 0.421 & $\mathrm{~T}$ & $\mathrm{~T}$ & $\mathrm{~T}$ \\
& $\mathrm{~d} 4$ & 0.574 & 0.503 & 0.558 & 0.659 & $\mathrm{~F}$ & $\mathrm{~F}$ & $\mathrm{~T}$ \\
& $\mathrm{~d} 5$ & 0.996 & 0.993 & 0.998 & 0.999 & $\mathrm{~F}$ & $\mathrm{~T}$ & $\mathrm{~T}$ \\
Feb 2001- & & & & & & & & \\
Apr 2002 & $\mathrm{d} 1$ & 0.223 & 0.141 & 0.157 & 0.188 & $\mathrm{~F}$ & $\mathrm{~F}$ & $\mathrm{~F}$ \\
& $\mathrm{~d} 2$ & 0.340 & 0.198 & 0.220 & 0.265 & $\mathrm{~F}$ & $\mathrm{~F}$ & $\mathrm{~F}$ \\
& $\mathrm{~d} 3$ & 0.480 & 0.291 & 0.325 & 0.390 & $\mathrm{~F}$ & $\mathrm{~F}$ & $\mathrm{~F}$ \\
& $\mathrm{~d} 4$ & 0.757 & 0.442 & 0.489 & 0.586 & $\mathrm{~F}$ & $\mathrm{~F}$ & $\mathrm{~F}$ \\
& $\mathrm{~d} 5$ & 0.745 & 0.901 & 0.948 & 0.988 & $\mathrm{~T}$ & $\mathrm{~T}$ & $\mathrm{~T}$ \\
& & & & & & & & \\
\hline
\end{tabular}

Note: An Inclan-Tiao approximation is used to compute the critical values for sample sizes $\mathrm{N} \geq 128$, while a Monte Carlo Technique is used for $\mathrm{N}<128$. "T" indicates that we cannot reject the null hypothesis and " $\mathrm{F}$ " otherwise. 
(b) 60 days

\begin{tabular}{|c|c|c|ccc|ccc|}
\hline Period & Scale & D-statistic & \multicolumn{3}{|c|}{ Critical Values } & \multicolumn{3}{c|}{$\mathrm{H}_{0}$ : Homogeneity } \\
& & & $10 \%$ & $5 \%$ & $1 \%$ & $10 \%$ & $5 \%$ & $1 \%$ \\
\hline \multirow{2}{*}{ 2000-Jan 2001 } & & & & & & & & \\
& & & & & & & & \\
& $\mathrm{d} 2$ & 0.141 & 0.152 & 0.169 & 0.203 & $\mathrm{~T}$ & $\mathrm{~T}$ & $\mathrm{~T}$ \\
& $\mathrm{~d} 3$ & 0.292 & 0.315 & 0.351 & 0.421 & $\mathrm{~T}$ & $\mathrm{~T}$ & $\mathrm{~T}$ \\
& $\mathrm{~d} 4$ & 0.456 & 0.503 & 0.558 & 0.659 & $\mathrm{~T}$ & $\mathrm{~T}$ & $\mathrm{~T}$ \\
& $\mathrm{~d} 5$ & 0.891 & 0.993 & 0.998 & 0.999 & $\mathrm{~T}$ & $\mathrm{~T}$ & $\mathrm{~T}$ \\
Feb 2001- & & & & & & & & \\
& $\mathrm{d} 1$ & 0.272 & 0.141 & 0.157 & 0.188 & $\mathrm{~F}$ & $\mathrm{~F}$ & $\mathrm{~F}$ \\
& $\mathrm{~d} 2$ & 0.343 & 0.198 & 0.220 & 0.265 & $\mathrm{~F}$ & $\mathrm{~F}$ & $\mathrm{~F}$ \\
& $\mathrm{~d} 3$ & 0.438 & 0.291 & 0.325 & 0.390 & $\mathrm{~F}$ & $\mathrm{~F}$ & $\mathrm{~F}$ \\
& $\mathrm{~d} 4$ & 0.343 & 0.442 & 0.489 & 0.586 & $\mathrm{~T}$ & $\mathrm{~T}$ & $\mathrm{~T}$ \\
& $\mathrm{~d} 5$ & 0.665 & 0.901 & 0.948 & 0.988 & $\mathrm{~T}$ & $\mathrm{~T}$ & $\mathrm{~T}$ \\
\hline
\end{tabular}

Note: An Inclan-Tiao approximation is used to compute the critical values for sample sizes $\mathrm{N} \geq 128$, while a Monte Carlo Technique is used for $\mathrm{N}<128$. "T" indicates that we cannot reject the null hypothesis and "F" otherwise. 
(b) 90 days

\begin{tabular}{|c|c|c|ccc|ccc|}
\hline \multirow{2}{*}{ Period } & \multirow{2}{*}{ Scale } & D-statistic & \multicolumn{4}{|c|}{ Critical Values } & \multicolumn{4}{|c|}{$\mathrm{H}_{0}$ : Homogeneity } \\
& & & $10 \%$ & $5 \%$ & $1 \%$ & $10 \%$ & $5 \%$ & $1 \%$ \\
\hline \multirow{2}{*}{ 2000-Jan 2001 } & d1 & 0.314 & 0.152 & 0.169 & 0.203 & $\mathrm{~F}$ & $\mathrm{~F}$ & $\mathrm{~F}$ \\
& $\mathrm{~d} 2$ & 0.238 & 0.213 & 0.236 & 0.287 & $\mathrm{~F}$ & $\mathrm{~F}$ & $\mathrm{~T}$ \\
& $\mathrm{~d} 3$ & 0.378 & 0.315 & 0.351 & 0.421 & $\mathrm{~F}$ & $\mathrm{~F}$ & $\mathrm{~T}$ \\
& $\mathrm{~d} 4$ & 0.343 & 0.503 & 0.558 & 0.659 & $\mathrm{~T}$ & $\mathrm{~T}$ & $\mathrm{~T}$ \\
& $\mathrm{~d} 5$ & 0.989 & 0.993 & 0.998 & 0.999 & $\mathrm{~T}$ & $\mathrm{~T}$ & $\mathrm{~T}$ \\
\hline \multirow{3}{*}{ Feb 2001- } & & & & & & & & \\
Apr 2002 & $\mathrm{d} 1$ & 0.322 & 0.143 & 0.158 & 0.190 & $\mathrm{~F}$ & $\mathrm{~F}$ & $\mathrm{~F}$ \\
& $\mathrm{~d} 2$ & 0.288 & 0.200 & 0.223 & 0.268 & $\mathrm{~F}$ & $\mathrm{~F}$ & $\mathrm{~F}$ \\
& $\mathrm{~d} 3$ & 0.323 & 0.295 & 0.329 & 0.394 & $\mathrm{~F}$ & $\mathrm{~T}$ & $\mathrm{~T}$ \\
& $\mathrm{~d} 4$ & 0.308 & 0.459 & 0.508 & 0.608 & $\mathrm{~T}$ & $\mathrm{~T}$ & $\mathrm{~T}$ \\
& $\mathrm{~d} 5$ & 0.430 & 0.901 & 0.948 & 0.988 & $\mathrm{~T}$ & $\mathrm{~T}$ & $\mathrm{~T}$ \\
\hline
\end{tabular}

Note: An Inclan-Tiao approximation is used to compute the critical values for sample sizes $\mathrm{N} \geq 128$, while a Monte Carlo Technique is used for $\mathrm{N}<128$. "T" indicates that we cannot reject the null hypothesis and " $\mathrm{F}$ " otherwise. 
(b) 180 days

\begin{tabular}{|c|c|c|ccc|cccc|}
\hline Period & Scale & D-statistic & \multicolumn{3}{|c|}{ Critical Values } & \multicolumn{3}{c|}{$\mathrm{H}_{0}$ : Homogeneity } \\
& & & $10 \%$ & $5 \%$ & $1 \%$ & $10 \%$ & $5 \%$ & $1 \%$ \\
\hline \multirow{2}{*}{ 2000-Jan 2001 } & & & & & & & & \\
& & & & & & & & \\
& $\mathrm{d}$ 2 & 0.308 & 0.152 & 0.169 & 0.203 & $\mathrm{~F}$ & $\mathrm{~F}$ & $\mathrm{~F}$ \\
& $\mathrm{~d} 3$ & 0.86 & 0.213 & 0.236 & 0.287 & $\mathrm{~F}$ & $\mathrm{~F}$ & $\mathrm{~F}$ \\
& $\mathrm{~d} 4$ & 0.292 & 0.503 & 0.558 & 0.659 & $\mathrm{~T}$ & $\mathrm{~T}$ & $\mathrm{~T}$ \\
& $\mathrm{~d} 5$ & 0.747 & 0.993 & 0.998 & 0.999 & $\mathrm{~T}$ & $\mathrm{~T}$ & $\mathrm{~T}$ \\
\hline Feb 2001- & & & & & & & & \\
& $\mathrm{d} 1$ & 0.284 & 0.143 & 0.158 & 0.190 & $\mathrm{~F}$ & $\mathrm{~F}$ & $\mathrm{~F}$ \\
& $\mathrm{~d} 2$ & 0.183 & 0.200 & 0.223 & 0.268 & $\mathrm{~T}$ & $\mathrm{~T}$ & $\mathrm{~T}$ \\
& $\mathrm{~d} 3$ & 0.264 & 0.295 & 0.329 & 0.394 & $\mathrm{~T}$ & $\mathrm{~T}$ & $\mathrm{~T}$ \\
& $\mathrm{~d} 4$ & 0.427 & 0.459 & 0.508 & 0.608 & $\mathrm{~T}$ & $\mathrm{~T}$ & $\mathrm{~T}$ \\
& $\mathrm{~d} 5$ & 0.433 & 0.901 & 0.948 & 0.988 & $\mathrm{~T}$ & $\mathrm{~T}$ & $\mathrm{~T}$ \\
\hline
\end{tabular}

Note: An Inclan-Tiao approximation is used to compute the critical values for sample sizes $\mathrm{N} \geq 128$, while a Monte Carlo Technique is used for $\mathrm{N}<128$. "T" indicates that we cannot reject the null hypothesis and " $\mathrm{F}$ " otherwise.

The next step was to remove serial correlation and conditional heteroskedasticity from the series by a $\operatorname{GARCH}(1,1)$ model, in which the mean equation includes one lag of the dependent variable. Surprisingly, this time the ICSS algorithm did not find any volatility breakpoints over 1997-2002 in any of the stock return series. Therefore, the presence of conditional heteroskedascity would be driving the results reported in Table 4 for the most part. (In general, serial correlation in daily returns is low). Regarding interest rates, the ICSS algorithm still detects some variance shifts: January 2001 and April 2001 for the 30-day interest rate, August 2001 for the 60-day interest rate, January 2000 and March 2001 for the 90-day interest rate. For the 180-day interest rate, however, no breaks are found. It is interesting to see that for the 90-day interest rate, the number of breakpoints detected is substantially reduced. This again suggests that conditional heteroskedasticity played an important role in our previous conclusions. 
With respect to wavelet analysis, some evidence against the null hypothesis of variance homogeneity is found in three indices for 1997-1998. Specifically, the null hypothesis is rejected for Europe at scale 2 at the 10 percent significance level, for Latin America at scales 1, 2, 5 and 6 at the 10 percent significance level, and for North America at scale 4 at the 5 percent significance level. In other words, the Asian crisis would have caused variance shifts elsewhere, after controlling for conditional heteroskedasticity. Over 1999-2002, no breaks are found in any filtered series at any scale (Table 4).

\section{Table 4}

Volatility shifts test after controlling for conditional heteroskedasticity:

Stock indices

(a) Emerging Asia

\begin{tabular}{|c|c|c|ccc|ccc|}
\hline Period & Scale & D-statistic & \multicolumn{3}{|c|}{ Critical Values } & \multicolumn{3}{c|}{$\mathrm{H}_{0}$ : Homogeneity } \\
& & & $10 \%$ & $5 \%$ & $1 \%$ & $10 \%$ & $5 \%$ & $1 \%$ \\
\hline \multirow{3}{*}{ 1997-1998 } & & & & & & & & \\
& & 0.044 & 0.108 & 0.120 & 0.144 & $\mathrm{~T}$ & $\mathrm{~T}$ & $\mathrm{~T}$ \\
& $\mathrm{~d} 2$ & 0.132 & 0.151 & 0.167 & 0.202 & $\mathrm{~T}$ & $\mathrm{~T}$ & $\mathrm{~T}$ \\
& $\mathrm{~d} 3$ & 0.141 & 0.218 & 0.243 & 0.295 & $\mathrm{~T}$ & $\mathrm{~T}$ & $\mathrm{~T}$ \\
& $\mathrm{~d} 4$ & 0.112 & 0.319 & 0.355 & 0.428 & $\mathrm{~T}$ & $\mathrm{~T}$ & $\mathrm{~T}$ \\
& $\mathrm{~d} 5$ & 0.197 & 0.503 & 0.558 & 0.659 & $\mathrm{~T}$ & $\mathrm{~T}$ & $\mathrm{~T}$ \\
& $\mathrm{~d} 6$ & 0.867 & 0.993 & 0.998 & 0.999 & $\mathrm{~T}$ & $\mathrm{~T}$ & $\mathrm{~T}$ \\
& $\mathrm{~d} 1$ & 0.010 & 0.077 & 0.085 & 0.101 & $\mathrm{~T}$ & $\mathrm{~T}$ & $\mathrm{~T}$ \\
& $\mathrm{~d} 2$ & 0.061 & 0.109 & 0.121 & 0.144 & $\mathrm{~T}$ & $\mathrm{~T}$ & $\mathrm{~T}$ \\
& $\mathrm{~d} 3$ & 0.094 & 0.152 & 0.168 & 0.203 & $\mathrm{~T}$ & $\mathrm{~T}$ & $\mathrm{~T}$ \\
& $\mathrm{~d} 4$ & 0.119 & 0.218 & 0.243 & 0.295 & $\mathrm{~T}$ & $\mathrm{~T}$ & $\mathrm{~T}$ \\
& $\mathrm{~d} 5$ & 0.266 & 0.319 & 0.355 & 0.428 & $\mathrm{~T}$ & $\mathrm{~T}$ & $\mathrm{~T}$ \\
& $\mathrm{~d} 6$ & 0.346 & 0.503 & 0.558 & 0.659 & $\mathrm{~T}$ & $\mathrm{~T}$ & $\mathrm{~T}$ \\
\hline
\end{tabular}

Note: An Inclan-Tiao approximation is used to compute the critical values for sample sizes $\mathrm{N} \geq 128$, while a Monte Carlo Technique is used for $\mathrm{N}<128$. " $\mathrm{T}$ " indicates that we cannot reject the null hypothesis and "F" otherwise. 
(b) Europe

\begin{tabular}{|c|c|c|c|c|c|c|c|c|}
\hline \multirow{2}{*}{ Period } & \multirow[t]{2}{*}{ Scale } & \multirow[t]{2}{*}{ D-statistic } & \multicolumn{3}{|c|}{ Critical Values } & \multicolumn{3}{|c|}{$\mathrm{H}_{0}:$ Homogeneity } \\
\hline & & & $10 \%$ & $5 \%$ & $1 \%$ & $10 \%$ & $5 \%$ & $1 \%$ \\
\hline \multirow[t]{6}{*}{ 1997-1998 } & d1 & 0.041 & 0.108 & 0.120 & 0.144 & $\mathrm{~T}$ & $\mathrm{~T}$ & $\mathrm{~T}$ \\
\hline & $\mathrm{d} 2$ & 0.151 & 0.151 & 0.167 & 0.202 & $\mathrm{~F}$ & $\mathrm{~T}$ & $\mathrm{~T}$ \\
\hline & $\mathrm{d} 3$ & 0.100 & 0.218 & 0.243 & 0.295 & $\mathrm{~T}$ & $\mathrm{~T}$ & $\mathrm{~T}$ \\
\hline & $\mathrm{d} 4$ & 0.196 & 0.319 & 0.355 & 0.428 & $\mathrm{~T}$ & $\mathrm{~T}$ & $\mathrm{~T}$ \\
\hline & d5 & 0.317 & 0.503 & 0.558 & 0.659 & $\mathrm{~T}$ & $\mathrm{~T}$ & $\mathrm{~T}$ \\
\hline & d6 & 0.740 & 0.993 & 0.998 & 0.999 & $\mathrm{~T}$ & $\mathrm{~T}$ & $\mathrm{~T}$ \\
\hline \multirow[t]{5}{*}{$1999-2000$} & d1 & 0.100 & 0.149 & 0.167 & 0.200 & $\mathrm{~T}$ & $\mathrm{~T}$ & $\mathrm{~T}$ \\
\hline & d2 & 0.080 & 0.214 & 0.239 & 0.290 & $\mathrm{~T}$ & $\mathrm{~T}$ & $\mathrm{~T}$ \\
\hline & d3 & 0.109 & 0.319 & 0.355 & 0.428 & $\mathrm{~T}$ & $\mathrm{~T}$ & $\mathrm{~T}$ \\
\hline & d4 & 0.448 & 0.503 & 0.558 & 0.659 & $\mathrm{~T}$ & $\mathrm{~T}$ & $\mathrm{~T}$ \\
\hline & d5 & 0.590 & 0.993 & 0.998 & 0.999 & $\mathrm{~T}$ & $\mathrm{~T}$ & $\mathrm{~T}$ \\
\hline \multirow[t]{6}{*}{2001} & dl & 0.066 & 0.108 & 0.120 & 0.144 & $\mathrm{~T}$ & $\mathrm{~T}$ & $\mathrm{~T}$ \\
\hline & $\mathrm{d} 2$ & 0.052 & 0.151 & 0.167 & 0.202 & $\mathrm{~T}$ & $\mathrm{~T}$ & $\mathrm{~T}$ \\
\hline & d3 & 0.108 & 0.218 & 0.243 & 0.295 & $\mathrm{~T}$ & $\mathrm{~T}$ & $\mathrm{~T}$ \\
\hline & d4 & 0.299 & 0.319 & 0.355 & 0.428 & $\mathrm{~T}$ & $\mathrm{~T}$ & $\mathrm{~T}$ \\
\hline & d5 & 0.186 & 0.503 & 0.558 & 0.659 & $\mathrm{~T}$ & $\mathrm{~T}$ & $\mathrm{~T}$ \\
\hline & d6 & 0.974 & 0.993 & 0.998 & 0.999 & $\mathrm{~T}$ & $\mathrm{~T}$ & $\mathrm{~T}$ \\
\hline \multirow[t]{5}{*}{ 2001-2002 } & d1 & 0.074 & 0.149 & 0.167 & 0.200 & $\mathrm{~T}$ & $\mathrm{~T}$ & $\mathrm{~T}$ \\
\hline & d2 & 0.201 & 0.214 & 0.239 & 0.290 & $\mathrm{~T}$ & $\mathrm{~T}$ & $\mathrm{~T}$ \\
\hline & $\mathrm{d} 3$ & 0.157 & 0.319 & 0.355 & 0.428 & $\mathrm{~T}$ & $\mathrm{~T}$ & $\mathrm{~T}$ \\
\hline & $\mathrm{d} 4$ & 0.200 & 0.503 & 0.558 & 0.659 & $\mathrm{~T}$ & $\mathrm{~T}$ & $\mathrm{~T}$ \\
\hline & d5 & 0.993 & 0.993 & 0.998 & 0.999 & $\mathrm{~T}$ & $\mathrm{~T}$ & $\mathrm{~T}$ \\
\hline
\end{tabular}

Note: An Inclan-Tiao approximation is used to compute the critical values for sample sizes $\mathrm{N} \geq 128$, while a Monte Carlo Technique is used for $\mathrm{N}<128$. "T" indicates that we cannot reject the null hypothesis and "F" otherwise. 
(c) Latin America

\begin{tabular}{|c|c|c|c|c|c|c|c|c|}
\hline \multirow[t]{2}{*}{ Period } & \multirow[t]{2}{*}{ Scale } & \multirow[t]{2}{*}{ D-statistic } & \multicolumn{3}{|c|}{ Critical Values } & \multicolumn{3}{|c|}{$\mathrm{H}_{0}:$ Homogeneity } \\
\hline & & & $10 \%$ & $5 \%$ & $1 \%$ & $10 \%$ & $5 \%$ & $1 \%$ \\
\hline \multirow[t]{6}{*}{$1997-1998$} & dl & 0.109 & 0.108 & 0.120 & 0.144 & $\mathrm{~F}$ & $\mathrm{~T}$ & $\mathrm{~T}$ \\
\hline & d2 & 0.155 & 0.151 & 0.167 & 0.202 & $\mathrm{~F}$ & $\mathrm{~T}$ & $\mathrm{~T}$ \\
\hline & d3 & 0.198 & 0.218 & 0.243 & 0.295 & $\mathrm{~T}$ & $\mathrm{~T}$ & $\mathrm{~T}$ \\
\hline & $\mathrm{d} 4$ & 0.164 & 0.319 & 0.355 & 0.428 & $\mathrm{~T}$ & $\mathrm{~T}$ & $\mathrm{~T}$ \\
\hline & d5 & 0.545 & 0.503 & 0.558 & 0.659 & $\mathrm{~F}$ & $\mathrm{~T}$ & $\mathrm{~T}$ \\
\hline & d6 & 0.998 & 0.993 & 0.998 & 0.999 & $\mathrm{~F}$ & $\mathrm{~T}$ & $\mathrm{~T}$ \\
\hline \multirow[t]{6}{*}{$1999-2001$} & dl & 0.070 & 0.088 & 0.098 & 0.117 & $\mathrm{~T}$ & $\mathrm{~T}$ & $\mathrm{~T}$ \\
\hline & $\mathrm{d} 2$ & 0.092 & 0.126 & 0.140 & 0.167 & $\mathrm{~T}$ & $\mathrm{~T}$ & $\mathrm{~T}$ \\
\hline & $\mathrm{d} 3$ & 0.115 & 0.176 & 0.195 & 0.232 & $\mathrm{~T}$ & $\mathrm{~T}$ & $\mathrm{~T}$ \\
\hline & $\mathrm{d} 4$ & 0.162 & 0.256 & 0.284 & 0.342 & $\mathrm{~T}$ & $\mathrm{~T}$ & $\mathrm{~T}$ \\
\hline & d5 & 0.328 & 0.381 & 0.425 & 0.505 & $\mathrm{~T}$ & $\mathrm{~T}$ & $\mathrm{~T}$ \\
\hline & d6 & 0.475 & 0.636 & 0.703 & 0.815 & $\mathrm{~T}$ & $\mathrm{~T}$ & $\mathrm{~T}$ \\
\hline \multirow[t]{6}{*}{$1999-2002$} & dl & 0.052 & 0.077 & 0.085 & 0.101 & $\mathrm{~T}$ & $\mathrm{~T}$ & $\mathrm{~T}$ \\
\hline & $\mathrm{d} 2$ & 0.088 & 0.109 & 0.121 & 0.144 & $\mathrm{~T}$ & $\mathrm{~T}$ & $\mathrm{~T}$ \\
\hline & d3 & 0.116 & 0.152 & 0.168 & 0.203 & $\mathrm{~T}$ & $\mathrm{~T}$ & $\mathrm{~T}$ \\
\hline & $\mathrm{d} 4$ & 0.114 & 0.218 & 0.243 & 0.295 & $\mathrm{~T}$ & $\mathrm{~T}$ & $\mathrm{~T}$ \\
\hline & d5 & 0.213 & 0.319 & 0.355 & 0.428 & $\mathrm{~T}$ & $\mathrm{~T}$ & $\mathrm{~T}$ \\
\hline & d6 & 0.232 & 0.503 & 0.558 & 0.659 & $\mathrm{~T}$ & $\mathrm{~T}$ & $\mathrm{~T}$ \\
\hline
\end{tabular}

Note: An Inclan-Tiao approximation is used to compute the critical values for sample sizes $\mathrm{N} \geq 128$, while a Monte Carlo Technique is used for $\mathrm{N}<128$. " $\mathrm{T}$ " indicates that we cannot reject the null hypothesis and "F" otherwise. 
(d) North America

\begin{tabular}{|c|c|c|c|c|c|c|c|c|}
\hline \multirow[t]{2}{*}{ Period } & \multirow[t]{2}{*}{ Scale } & \multirow[t]{2}{*}{ D-statistic } & \multicolumn{3}{|c|}{ Critical Values } & \multicolumn{3}{|c|}{$\mathrm{H}_{0}:$ Homogeneity } \\
\hline & & & $10 \%$ & $5 \%$ & $1 \%$ & $10 \%$ & $5 \%$ & $1 \%$ \\
\hline \multirow[t]{6}{*}{ 1997-1998 } & d1 & 0.103 & 0.108 & 0.120 & 0.144 & $\mathrm{~T}$ & $\mathrm{~T}$ & $\mathrm{~T}$ \\
\hline & $\mathrm{d} 2$ & 0.066 & 0.151 & 0.167 & 0.202 & $\mathrm{~T}$ & $\mathrm{~T}$ & $\mathrm{~T}$ \\
\hline & $\mathrm{d} 3$ & 0.092 & 0.218 & 0.243 & 0.295 & $\mathrm{~T}$ & $\mathrm{~T}$ & $\mathrm{~T}$ \\
\hline & $\mathrm{d} 4$ & 0.391 & 0.319 & 0.355 & 0.428 & $\mathrm{~F}$ & $\mathrm{~F}$ & $\mathrm{~T}$ \\
\hline & d5 & 0.316 & 0.503 & 0.558 & 0.659 & $\mathrm{~T}$ & $\mathrm{~T}$ & $\mathrm{~T}$ \\
\hline & d6 & 0.984 & 0.993 & 0.998 & 0.999 & $\mathrm{~T}$ & $\mathrm{~T}$ & $\mathrm{~T}$ \\
\hline \multirow[t]{6}{*}{ 1999-2001 } & $\mathrm{d} 1$ & 0.056 & 0.088 & 0.098 & 0.117 & $\mathrm{~T}$ & $\mathrm{~T}$ & $\mathrm{~T}$ \\
\hline & $\mathrm{d} 2$ & 0.120 & 0.126 & 0.140 & 0.167 & $\mathrm{~T}$ & $\mathrm{~T}$ & $\mathrm{~T}$ \\
\hline & $\mathrm{d} 3$ & 0.125 & 0.176 & 0.195 & 0.232 & $\mathrm{~T}$ & $\mathrm{~T}$ & $\mathrm{~T}$ \\
\hline & $\mathrm{d} 4$ & 0.131 & 0.256 & 0.284 & 0.342 & $\mathrm{~T}$ & $\mathrm{~T}$ & $\mathrm{~T}$ \\
\hline & d5 & 0.232 & 0.381 & 0.425 & 0.505 & $\mathrm{~T}$ & $\mathrm{~T}$ & $\mathrm{~T}$ \\
\hline & d6 & 0.598 & 0.636 & 0.703 & 0.815 & $\mathrm{~T}$ & $\mathrm{~T}$ & $\mathrm{~T}$ \\
\hline \multirow[t]{6}{*}{$1999-2002$} & dl & 0.058 & 0.077 & 0.085 & 0.101 & $\mathrm{~T}$ & $\mathrm{~T}$ & $\mathrm{~T}$ \\
\hline & $\mathrm{d} 2$ & 0.0944 & 0.109 & 0.121 & 0.144 & $\mathrm{~T}$ & $\mathrm{~T}$ & $\mathrm{~T}$ \\
\hline & $\mathrm{d} 3$ & 0.088 & 0.152 & 0.168 & 0.203 & $\mathrm{~T}$ & $\mathrm{~T}$ & $\mathrm{~T}$ \\
\hline & $\mathrm{d} 4$ & 0.169 & 0.218 & 0.243 & 0.295 & $\mathrm{~T}$ & $\mathrm{~T}$ & $\mathrm{~T}$ \\
\hline & d5 & 0.166 & 0.319 & 0.355 & 0.428 & $\mathrm{~T}$ & $\mathrm{~T}$ & $\mathrm{~T}$ \\
\hline & d6 & 0.295 & 0.503 & 0.558 & 0.659 & $\mathrm{~T}$ & $\mathrm{~T}$ & $\mathrm{~T}$ \\
\hline
\end{tabular}

Note: An Inclan-Tiao approximation is used to compute the critical values for sample sizes $\mathrm{N} \geq 128$, while a Monte Carlo Technique is used for $\mathrm{N}<128$. " $\mathrm{T}$ " indicates that we cannot reject the null hypothesis and "F" otherwise.

Figure 4 illustrates the turbulence experienced by North America over JuneSeptember 1998. The left-hand side panel depicts recomposed crystal D4 - the component that would explain the violation of variance homogeneity over 19971998-, whereas the right-hand side panel shows the return series. The 95percent out-of-sample value at risk was computed by fitting a GARCH $(1,1)$ model to each series over January 1997-May 1998. As the right-hand shows, the accumulative actual loss on a $\$ 10,000$ portfolio invested on the North America index exceeds the 95-percent value at risk for about the first forty observations (June and mid-July). 


\section{Figure 4}

Out-of-Sample Value at Risk for North America: June-September 1998

Crystal D4

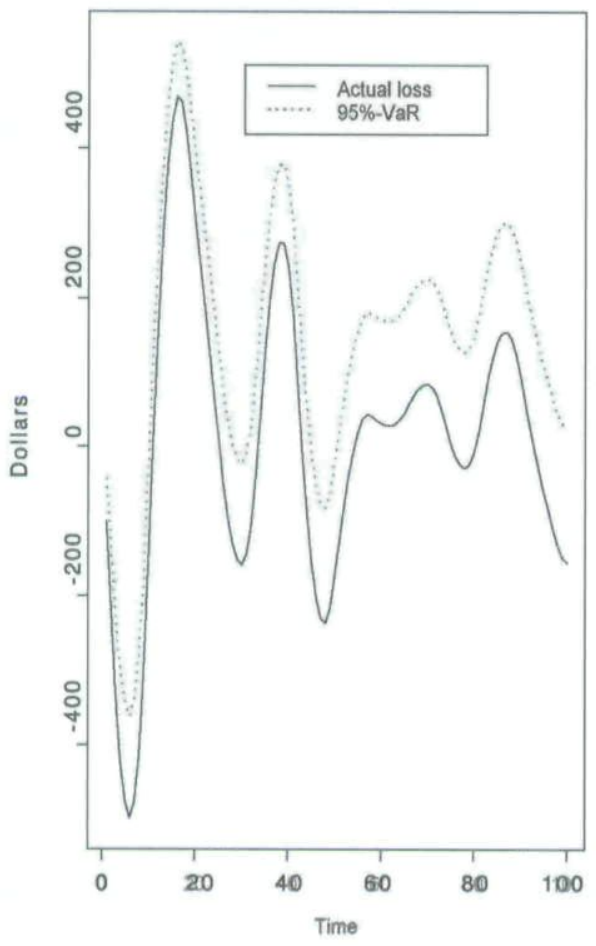

Data

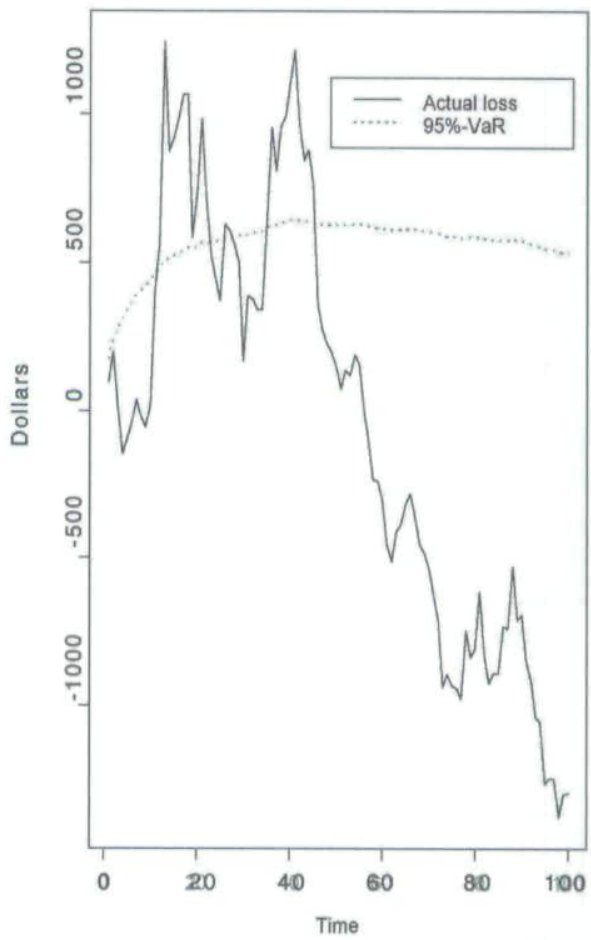

Note: The out-of sample value at risk is computed by fitting a $\operatorname{GARCH}(1,1)$ model to each series for January 1997-May 1998. The investment is $\$ 10,000$.

Regarding interest rates, breakpoints are still detected by the wavelet variance test after controlling for conditional heteroskedasticity and serial correlation (Table 5). In particular, there is evidence, at the 5 percent significance level, of variance shifts at scale 1 of the 30-day and 60-day interest rates over February 2001-April 2002. However, variance homogeneity is never rejected at any scale for the 90-day and 180-interest rates over the same period. That is to say, switching from an inflation-linked to a nominal monetary policy interest rate would have affected only the volatility of short nominal interest rates, according to this method. 
Table 5

Volatility shifts test after controlling for conditional heteroskedasticity: Interest rates

(a) 30 days

\begin{tabular}{|c|c|c|ccc|ccc|}
\hline \multirow{2}{*}{ Period } & Scale & D-statistic & \multicolumn{3}{|c|}{ Critical Values } & \multicolumn{3}{c|}{$\mathrm{H}_{0}$ : Homogeneity } \\
& & & $10 \%$ & $5 \%$ & $1 \%$ & $10 \%$ & $5 \%$ & $1 \%$ \\
\hline \multirow{2}{*}{ 2000-Jan 2001 } & d1 & 0.094 & 0.152 & 0.169 & 0.203 & $\mathrm{~T}$ & $\mathrm{~T}$ & $\mathrm{~T}$ \\
& $\mathrm{~d} 2$ & 0.194 & 0.213 & 0.236 & 0.287 & $\mathrm{~T}$ & $\mathrm{~T}$ & $\mathrm{~T}$ \\
& $\mathrm{~d} 3$ & 0.148 & 0.315 & 0.351 & 0.421 & $\mathrm{~T}$ & $\mathrm{~T}$ & $\mathrm{~T}$ \\
& $\mathrm{~d} 4$ & 0.603 & 0.503 & 0.558 & 0.659 & $\mathrm{~F}$ & $\mathrm{~F}$ & $\mathrm{~T}$ \\
& $\mathrm{~d} 5$ & 0.999 & 0.993 & 0.998 & 0.999 & $\mathrm{~F}$ & $\mathrm{~F}$ & $\mathrm{~T}$ \\
\hline Feb 2001- & & & & & & & & \\
Apr 2002 & $\mathrm{d} 1$ & 0.161 & 0.141 & 0.157 & 0.188 & $\mathrm{~F}$ & $\mathrm{~F}$ & $\mathrm{~T}$ \\
& $\mathrm{~d} 2$ & 0.155 & 0.198 & 0.220 & 0.265 & $\mathrm{~T}$ & $\mathrm{~T}$ & $\mathrm{~T}$ \\
& $\mathrm{~d} 3$ & 0.394 & 0.291 & 0.325 & 0.390 & $\mathrm{~F}$ & $\mathrm{~F}$ & $\mathrm{~F}$ \\
& $\mathrm{~d} 4$ & 0.584 & 0.442 & 0.489 & 0.586 & $\mathrm{~F}$ & $\mathrm{~F}$ & $\mathrm{~T}$ \\
& $\mathrm{~d} 5$ & 0.708 & 0.901 & 0.948 & 0.988 & $\mathrm{~T}$ & $\mathrm{~T}$ & $\mathrm{~T}$ \\
\hline
\end{tabular}

(b) 60 days

\begin{tabular}{|l|l|l|ccc|ccc|}
\hline \multicolumn{1}{|c|}{ Period } & Scale & D-statistic & \multicolumn{3}{|c|}{ Critical Values } & \multicolumn{3}{c|}{$\mathrm{H}_{0}$ : Homogeneity } \\
& & & $10 \%$ & $5 \%$ & $1 \%$ & $10 \%$ & $5 \%$ & $1 \%$ \\
\hline 2000-Jan & & & & & & & & \\
2001 & d1 & 0.079 & 0.152 & 0.169 & 0.203 & $\mathrm{~T}$ & $\mathrm{~T}$ & $\mathrm{~T}$ \\
& $\mathrm{~d} 2$ & 0.147 & 0.213 & 0.236 & 0.287 & $\mathrm{~T}$ & $\mathrm{~T}$ & $\mathrm{~T}$ \\
& $\mathrm{~d} 3$ & 0.178 & 0.315 & 0.351 & 0.421 & $\mathrm{~T}$ & $\mathrm{~T}$ & $\mathrm{~T}$ \\
& $\mathrm{~d} 4$ & 0.488 & 0.503 & 0.558 & 0.659 & $\mathrm{~T}$ & $\mathrm{~T}$ & $\mathrm{~T}$ \\
& $\mathrm{~d} 5$ & 0.858 & 0.993 & 0.998 & 0.999 & $\mathrm{~T}$ & $\mathrm{~T}$ & $\mathrm{~T}$ \\
\hline Feb 2001- & & & & & & & & \\
Apr 2002 & $\mathrm{d} 1$ & 0.158 & 0.141 & 0.157 & 0.188 & $\mathrm{~F}$ & $\mathrm{~F}$ & $\mathrm{~T}$ \\
& $\mathrm{~d} 2$ & 0.161 & 0.198 & 0.220 & 0.265 & $\mathrm{~T}$ & $\mathrm{~T}$ & $\mathrm{~T}$ \\
& $\mathrm{~d} 3$ & 0.337 & 0.291 & 0.325 & 0.390 & $\mathrm{~F}$ & $\mathrm{~F}$ & $\mathrm{~T}$ \\
& $\mathrm{~d} 4$ & 0.230 & 0.442 & 0.489 & 0.586 & $\mathrm{~T}$ & $\mathrm{~T}$ & $\mathrm{~T}$ \\
& $\mathrm{~d} 5$ & 0.676 & 0.901 & 0.948 & 0.988 & $\mathrm{~T}$ & $\mathrm{~T}$ & $\mathrm{~T}$ \\
\hline
\end{tabular}

Note: An Inclan-Tiao approximation is used to compute the critical values for sample sizes $\mathrm{N} \geq 128$, while a Monte Carlo Technique is used for $\mathrm{N}<128$. "T" indicates that we cannot reject the null hypothesis and " $F$ " otherwise. 
(c) 90 days

\begin{tabular}{|c|l|l|rrr|rrr|}
\hline Period & Scale & D-statistic & \multicolumn{3}{|c|}{ Critical Values } & \multicolumn{3}{c|}{$\mathrm{H}_{0}$ : Homogeneity } \\
& & & $10 \%$ & $5 \%$ & $1 \%$ & $10 \%$ & $5 \%$ & $1 \%$ \\
\hline \multirow{2}{*}{ 2000-Jan 2001 } & d1 & 0.174 & 0.152 & 0.169 & 0.203 & $\mathrm{~F}$ & $\mathrm{~F}$ & $\mathrm{~T}$ \\
& $\mathrm{~d} 2$ & 0.143 & 0.213 & 0.236 & 0.287 & $\mathrm{~T}$ & $\mathrm{~T}$ & $\mathrm{~T}$ \\
& $\mathrm{~d} 3$ & 0.379 & 0.315 & 0.351 & 0.421 & $\mathrm{~F}$ & $\mathrm{~F}$ & $\mathrm{~T}$ \\
& $\mathrm{~d} 4$ & 0.216 & 0.503 & 0.558 & 0.659 & $\mathrm{~T}$ & $\mathrm{~T}$ & $\mathrm{~T}$ \\
& $\mathrm{~d} 5$ & 0.972 & 0.993 & 0.998 & 0.999 & $\mathrm{~T}$ & $\mathrm{~T}$ & $\mathrm{~T}$ \\
\hline Feb 2001- & & & & & & & & \\
Apr 2002 & $\mathrm{d} 1$ & 0.069 & 0.143 & 0.158 & 0.190 & $\mathrm{~T}$ & $\mathrm{~T}$ & $\mathrm{~T}$ \\
& $\mathrm{~d} 2$ & 0.128 & 0.200 & 0.223 & 0.268 & $\mathrm{~T}$ & $\mathrm{~T}$ & $\mathrm{~T}$ \\
& $\mathrm{~d} 3$ & 0.160 & 0.295 & 0.329 & 0.394 & $\mathrm{~T}$ & $\mathrm{~T}$ & $\mathrm{~T}$ \\
& $\mathrm{~d} 4$ & 0.223 & 0.459 & 0.508 & 0.608 & $\mathrm{~T}$ & $\mathrm{~T}$ & $\mathrm{~T}$ \\
& $\mathrm{~d} 5$ & 0.470 & 0.901 & 0.948 & 0.988 & $\mathrm{~T}$ & $\mathrm{~T}$ & $\mathrm{~T}$ \\
\hline
\end{tabular}

(d) 180 days

\begin{tabular}{|c|c|c|ccc|ccc|}
\hline Period & Scale & D-statistic & \multicolumn{3}{|c|}{ Critical Values } & \multicolumn{3}{c|}{$\mathrm{H}_{0}$ : Homogeneity } \\
& & & $10 \%$ & $5 \%$ & $1 \%$ & $10 \%$ & $5 \%$ & $1 \%$ \\
\hline \multirow{3}{*}{ 2000-Jan 2001 } & & & & & & & & \\
& & & & & & & & \\
& & & & & & & \\
& d2 & 0.153 & 0.152 & 0.169 & 0.203 & $\mathrm{~F}$ & $\mathrm{~T}$ & $\mathrm{~T}$ \\
& $\mathrm{~d} 3$ & 0.364 & 0.213 & 0.236 & 0.287 & $\mathrm{~F}$ & $\mathrm{~T}$ & $\mathrm{~T}$ \\
& $\mathrm{~d} 4$ & 0.270 & 0.503 & 0.558 & 0.659 & $\mathrm{~T}$ & $\mathrm{~T}$ & $\mathrm{~T}$ \\
Feb 2001- & $\mathrm{d} 5$ & 0.733 & 0.993 & 0.998 & 0.999 & $\mathrm{~T}$ & $\mathrm{~T}$ & $\mathrm{~T}$ \\
& & & & & & & & \\
& $\mathrm{~d} 1$ & 0.135 & 0.143 & 0.158 & 0.190 & $\mathrm{~T}$ & $\mathrm{~T}$ & $\mathrm{~T}$ \\
& $\mathrm{~d} 2$ & 0.145 & 0.200 & 0.223 & 0.268 & $\mathrm{~T}$ & $\mathrm{~T}$ & $\mathrm{~T}$ \\
& $\mathrm{~d} 3$ & 0.132 & 0.295 & 0.329 & 0.394 & $\mathrm{~T}$ & $\mathrm{~T}$ & $\mathrm{~T}$ \\
& $\mathrm{~d} 4$ & 0.358 & 0.459 & 0.508 & 0.608 & $\mathrm{~T}$ & $\mathrm{~T}$ & $\mathrm{~T}$ \\
& $\mathrm{~d} 5$ & 0.394 & 0.901 & 0.948 & 0.988 & $\mathrm{~T}$ & $\mathrm{~T}$ & $\mathrm{~T}$ \\
\hline
\end{tabular}

Note: An Inclan-Tiao approximation is used to compute the critical values for sample sizes $\mathrm{N} \geq 128$, while a Monte Carlo Technique is used for $\mathrm{N}<128$. "T" indicates that we cannot reject the null hypothesis and "F" otherwise. 
An alternative way to test for structural stability is by using a Wald test of the sort in Hamilton (1994, chapter 14). In particular, if $\mathrm{n}$ is the sample size, and $\mathrm{n}_{0}$ is a known breakpoint, a Wald test of the null hypothesis that $\theta_{1}=\theta_{2}$, is given by

$\mathrm{n}\left(\hat{\theta}_{1, \mathrm{n}_{0}}-\hat{\theta}_{2, \mathrm{n}-\mathrm{n}_{0}}\right)^{\prime}\left(\pi^{-1} \hat{\mathrm{V}}_{1, \mathrm{n}_{0}}+(1-\pi)^{-1} \hat{\mathrm{V}}_{2, \mathrm{n}-\mathrm{n}_{0}}\right)^{-1}\left(\hat{\theta}_{1, \mathrm{n}_{0}}-\hat{\theta}_{2, \mathrm{n}-\mathrm{n}_{0}}\right) \stackrel{\mathrm{d}}{\longrightarrow} \chi^{2}(\mathrm{q})$

where $\pi \equiv \mathrm{n}_{n} / \mathrm{n}$, $\mathrm{q}$ is the dimension of both $\theta_{1}$ and $\theta_{2}, A \operatorname{Var}\left(\hat{\theta}_{1, \mathrm{n}_{0}}\right)=(\mathrm{n} \pi)^{-1} \hat{\mathrm{V}}_{1, \mathrm{n}_{0}}$, and $\operatorname{AVar}\left(\hat{\theta}_{2, n-n_{0}}\right)=(n(1-\pi))^{-1} \hat{V}_{2, n-n_{0}}$

We applied this test to the recomposed crystal D1 of the first difference of the 30-day and the 60-day interest rates. For that purpose, we fitted a GARCH(1,1) model to the D1 series for January 2000-January 2001, and a second model for February 2001-April 2002. The statistic in (14) was then computed in each case. For both series, we rejected the null hypothesis of stability of the parameter models. In particular, for both series, we found that the longrun daily volatility decreased for the second period: from 0.77 to 0.61 percent points per day for the 30 -day interest rates, and from 0.33 to 0.25 percent points per day for the 60-day interest rates. As documented by Morandé (2002), one effect of nominalization was to reduce the volatility of nominal interest rates vis-á-vis inflation-indexed interest rates.

\section{Conclusions}

In this article, we tested for the presence of structural breaks in volatility by two approaches: the Iterative Cumulative Sum of Squares (ICSS) algorithm and wavelet analysis. Specifically, we looked at the effect of the outbreak of the Asian crisis and the terrorist attacks of September 11, 2001 on Emerging Asia, Europe, Latin America and North America's stock markets volatility. In addition, we focused on the behavior of interest rates in Chile after the Central Bank changed its monetary policy interest rate from an inflation-indexed to a nominal target in August 2001.

Our estimation results show that the number of shifts detected by the two methods is substantially reduced by filtering out the data for both conditional heteroskedasticity and serial correlation. In particular, for the filtered stock data, the ICSS algorithm did not find any volatility shifts over 1997-2002, whereas wavelet analysis found evidence of volatility breakpoints at some given scales of the data only for 1997-1998 (Asian crisis). For interest rates, both methods detect breakpoints in volatility for the filtered first difference of the 30 -day and 
60-day series over February 2001-April 2002 (nominalization of the monetary policy interest rate). A Wald test for parameter stability reinforces this evidence for interest rates.

\section{REFERENCES}

AgGarwal, R., C. Inclan, and R. Leal (1999), "Volatility in Emerging Stock Markets."Journal of Financial and Quantitative Analysis 34 (1), 33-55.

Bacmann, J. and M. Dubois (2002), "Volatility in Emerging Stock Markets Revisited." Manuscript presented at the European Financial Management Association (EFMA) 2002 London Meeting. http://ssrn.com/abstract=313932

Bruce A. And H. Gao (1996), Applied Wavelet Analysis with S-Plus. Springer-Verlag.

Gençay R., B. Whitcher, And F. SElçuk (2002), "Multi-scale systematic risk." National Centre of Competence (NCCR) in Research Financial Valuation and Risk Management Working Paper No. 43.

InClan, C. And G. Tiao (1994), "Use of cumulative sums of squares for retrospective detection of changes in variance." Journal of the American Statistical Association 89, 913-923.

Morandé, F. (2002), “Nominalización de la Tasa de Política Monetaria: Debate y Consequencias." Cuadernos de Economía, The Latin American Journal No. 117, 239-252.

LamoureuX, C., and W. Lastrapes (1990), "Persistence in Variance, Structural Change, and the GARCH Model." Journal of Business and Economic Statistics 8(2), 225-234. 
Lee, Hahn Shik (2001A), "Price and Volatility Spillovers in Stock Markets: A Wavelet Analysis". Manuscript presented at the 2001 Australasian Meeting of the Econometric Society. (2001b), "Recent Advances in Wavelet Methods for

Economic Time Series," Journal of Economic Theory and Econometrics 7(1), 43-65.

NORSWORTHY J. D. Li AND R. GORENER (2000) "Wavelet-Based Analysis of Time Series: An Export from Engineering to Finance." Manuscript presented at the 2000 IEEE International Engineering Management Society Conference.

Percival, D. and A. Walden (2000), Wavelets Analysis for Time Series Analysis. Cambridge University Press, Cambridge, U.K.

Poon, S., and C. Granger (2003), "Forecasting Volatility in Financial Markets: A Review.” Journal of Economic Literature 41(2), 478-539.

Ramsey J., and C. Lampart (1998), "The Decomposition of Economic Relationships by Time Scale Using Wavelets: Expenditure and Income," Studies in Nonlinear Dynamics \& Econometrics 3(1), 23-42. 
Copyright of Estudios de Administración is the property of Estudios de Administracion and its content may not be copied or emailed to multiple sites or posted to a listserv without the copyright holder's express written permission. However, users may print, download, or email articles for individual use. 